NIPER-615

Distribution Category UC-122

\author{
Data Requirements and Acquisition for \\ Reservoir Characterization \\ Topical Report \\ NIPER--615 \\ DE93 000121 \\ By \\ Susan Jackson \\ Ming Ming Chang \\ Min Tham
}

March 1993

Work Performed Under Cooperative Agreement No. DE-FC22-83FE60149

\author{
Prepared for \\ U.S. Department of Energy \\ Assistant Secretary for Fossil Energy
}

Edith Allison, Project Manager

Bartlesville Project Office

P.O. Box 1398

Bartlesville, OK 74005

Prepared by

IIT Research Institute

National Institute for Petroleum and Energy Research

P.O. Box 2128

Bartlesville, OK 74005 


\section{TABLE OF CONTENTS}

EXECUTIVE SUMMARY

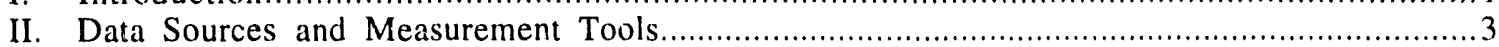

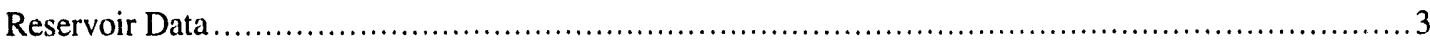

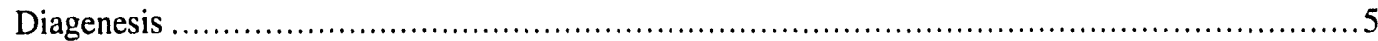

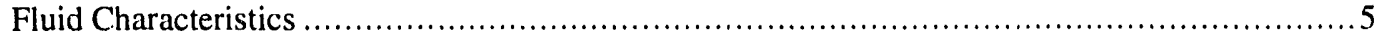

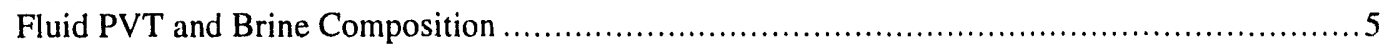

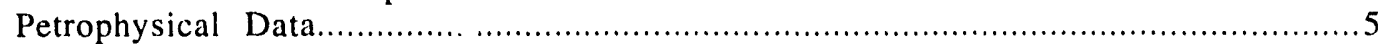

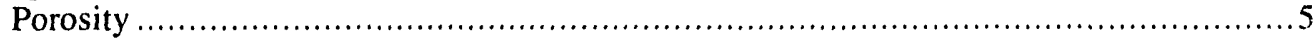

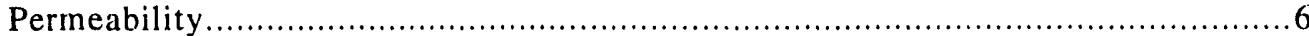

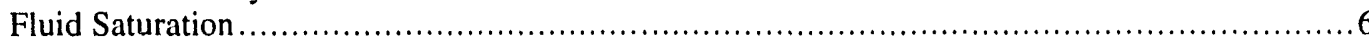

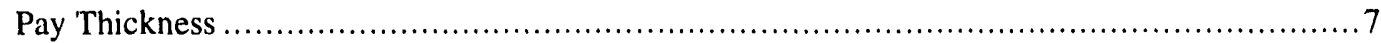

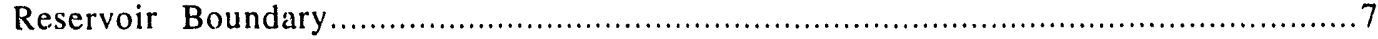

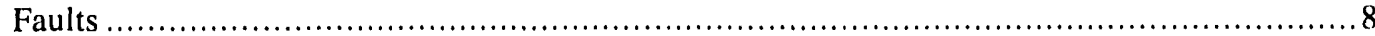

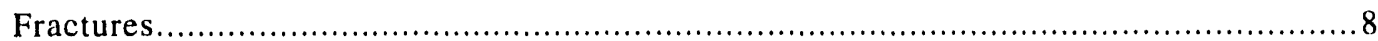

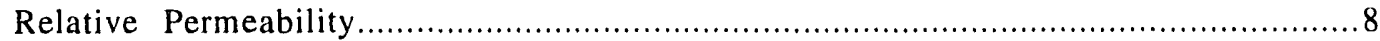

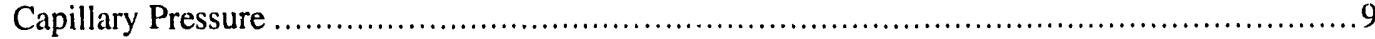

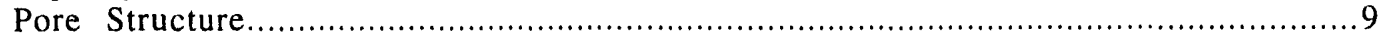

Production/Injection and Pressure Data ......................................................

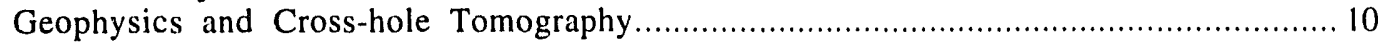

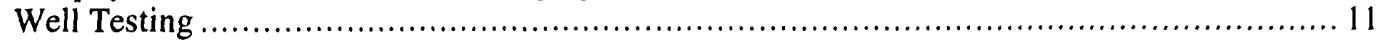

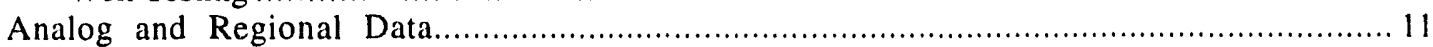

Outcrop Information ................................................................. 11

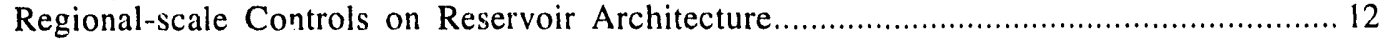

Location of Valley Fill Barriers.............................................................. 12

Regional Diagenetic Zone ............................................................... 14

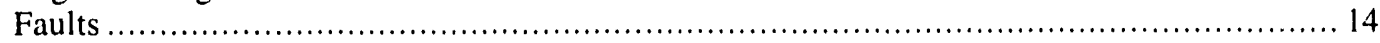

Relationship Between Structure and Diagenesis .......................................... 15

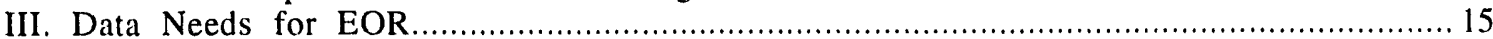

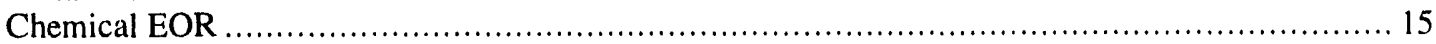

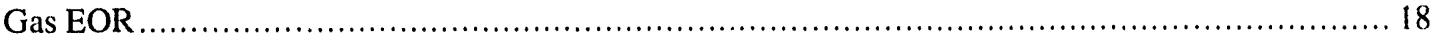

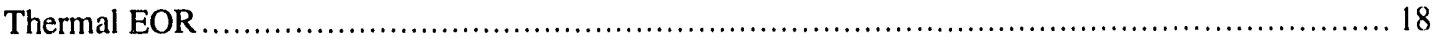

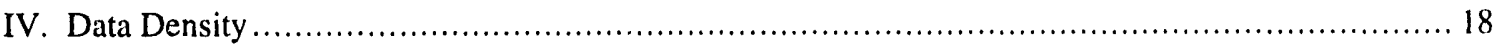

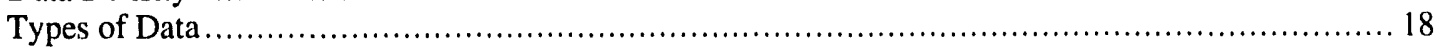

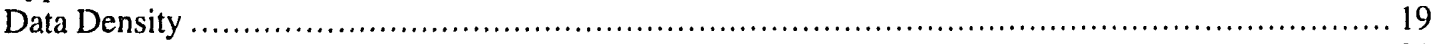

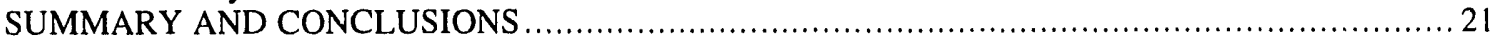

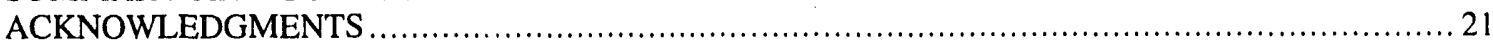

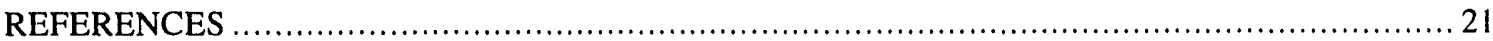

\section{TABLES}

1. Application of enhanced production methods to different scales of depositional-related heterogeneties .. 16

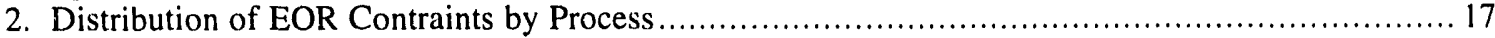

\section{ILLUSTRATIONS}

1. Type, sequence, and timing of data gathering for reservoir charactrization .............................

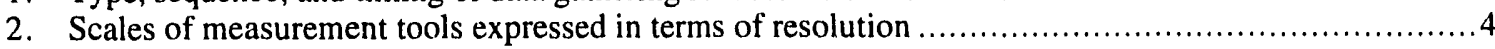

3. Degree of transferability of geological and reservoir properties between analogous deposits ..........13

4. Comparison of incremental data value and cost.................................................. 19

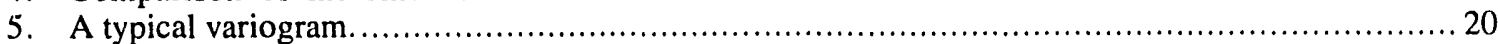

6. Permeability profile (a) and variogram (b) of core well No. 1, Almond outcrop, Sweetwater County, WY. 


\title{
DATA REQUIREMENTS AND ACQUISITION FOR RESERVOIR CHARACTERIZATION
}

\author{
B y \\ Susan Jackson, Ming Ming Chang and Min Tham
}

\section{EXECUTIVE SUMMARY}

This report outlines the types of data, data sources and measurement tools required for effective reservoir characterization, the data required for specific enhanced oil recovery (EOR) processes, and a discussion on the determination of the opiimum data density for reservoir characterization and reservoir modeling.

The two basic sources of data for reservoir characterization are data from the specific reservoir and data from analog reservoirs, outcrops, and modern environments. Reservoir data can be divided into three broad categories: (1) rock properties (the container) and (2) fluid properties (the contents) and (3) interaction between reservoir rock and fluid. Both static and dynamic measurements are required.

Reservoir characterization requires data on a range of scales from basin and field-scale information to pore-size information. Field-scale information establishes the spatial framework and the general architecture of the reservoir for describing and predicting smaller scale reservoir geometries and heterogeneities, along with their associated petrophysical and fluid-flow properties. Mesoscopic-scale information addresses variations of properties within the facies or reservoir units, while microscopic- or pore-scale information includes pore size, pore throat, surface roughness, grain size and sorting.

Outcrop exposures of reservoir rocks enable laterally continuous sampling of rock characteristics and provide lateral information on scales not available from reservoir data. Studies of outcrops and analogous modern environments can be valuable, low-cost sources of high quality, geological and petrophysical data. Outcrop studies can provide a wealth of quantitative information on the dimensions and geometries of sandbodies, fluid flow barriers forming compartments, permeability baffles, and the spatial distributions of matrix permeability and porosity. The constraint in applying outcrop data to reservoirs is the inability to determine the degree of transferability of characteristics between different deposits, even from the same depositional system.

Although much of the effort in reservoir characterization is focused on pore- to bedding-scale features, it is the larger scale reservoir architecture that controls the communication between wells and exerts a very strong influence on sweep and recovery efficiency. Regional-scale studies are essential for understanding the origin of the reservoir architecture and predicting the occurrence and location of heterogeneities. Examples are given to illustrate how the understanding of regional scale processes aid in predicting the location, orientation, and density of reservoir heterogeneity.
The scale of heterogeneities dominating production are different for different field development stages. As these stages progress from primary to secondary to tertiary recovery, the scale of important heterogeneities generally decreases and depends on the EOR process applied. The data required for the development and application of various EOR methods are presented.

The value of data can be assessed as the corresponding loss resulting from poor or incomplete data; however, determining the optimum data density for reservoir characterization is difficult because the value of the data may not be known until it is acquired and analyzed. Extensive simulation studies are needed to evaluate the magnitude and direction of errors that can be expected in oil recovery prediction with varying amounts of data. A quantitative approach using the variogram is proposed, where the correlation length is used as a guide to the minimum sampling distance for data collection.

\section{Introduction}

Reservoir characterization and the development of a reservoir management strategy for a field is an iterative process and should begin at the time the field is discovered (Honarpour, et al., 1990). As additional static and dynamic reservoir information is acquired, the management strategy should be adjusted or changed accordingly. Active collection of multidisciplinary data that is important to the design of future recovery processes must begin early in the life of a reservoir. Early collection of information that requires unaltered, natural-state reservoir conditions such as reservoir pressure and brine chemistry is especially important for EOR process design and is often neglected. Reservoir characterization essentially dictates the EOR strategy (Venuto, 1989), and must be an integral part of EOR planning and design. The type, sequence, and timing of data gathering for reservoir characterization is presented in figure 1.

Reservoirs are deterministic in nature in that only one actual representation exists for that particular reservoir. However, because it is not economically or technically feasible to completely sample a reservoir at all scales, the data set acquired must be, to a certain extent, statistical in nature. The models developed should reflect both the deterministic and the statistical nature of the data and be compatible with the geological understanding of the reservoirs. 


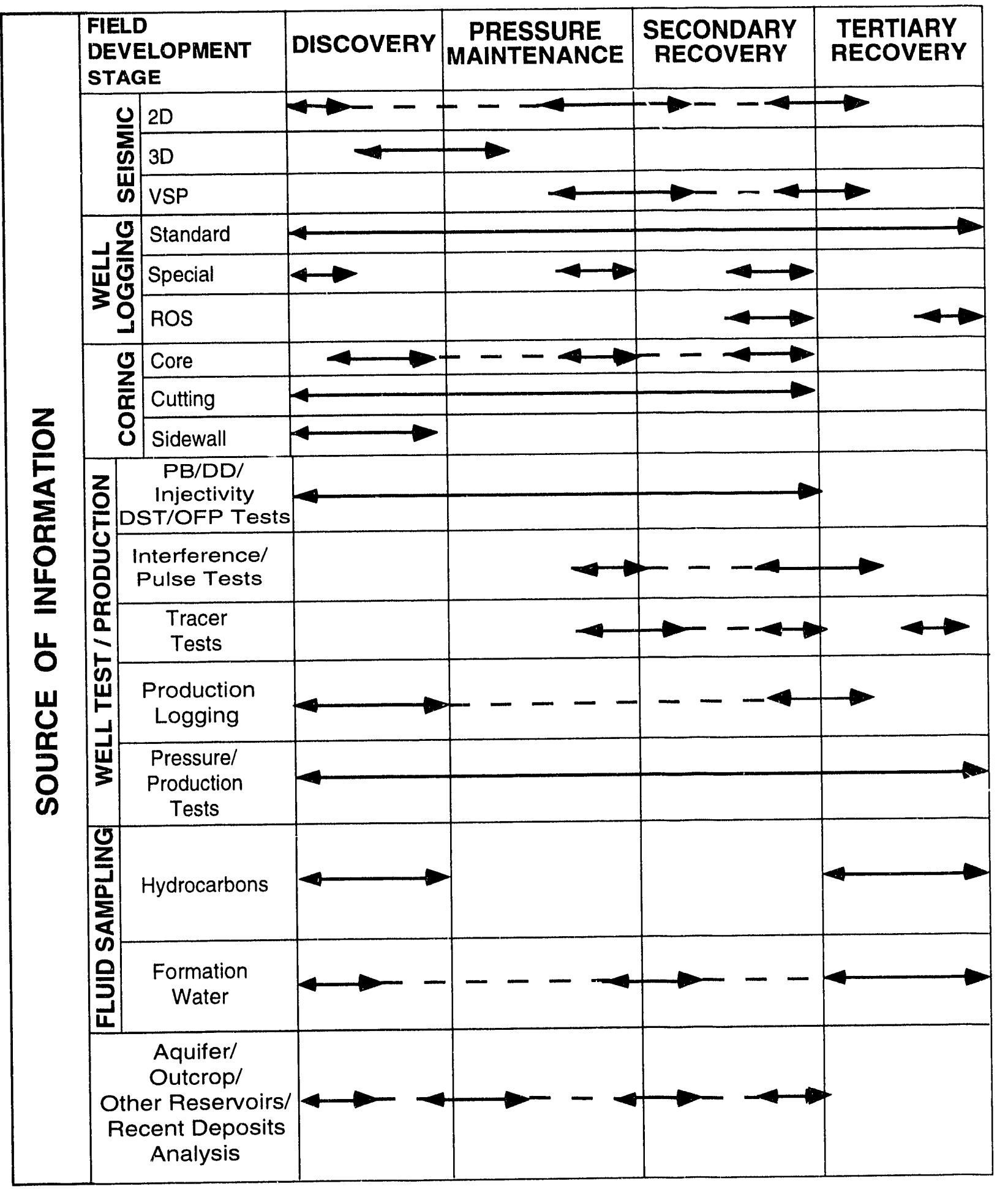

Fig. 1 Type, sequence, and timing of data gathering for reservoir characterization (modified from Weber, 1986). 
To determine data requirements, the cost and benefits of the additional data must be considered. This evaluation is complicated by the fact that all data are not of equal value, that there is a hierarchy in data acquisition, and that the benefit of additional data cannot be ascertained until the results are available (Saleri, et ai., 1991). The various issues to be addressed in data set requirements are: scales of heterogeneity, stages of field development and recovery process; timing of data acquisition; and need for a stochastic approach.

The various scales of heterogeneity control fluid flow, and other characteristics in a reservoir, in a manner that is directly related to the size and the part of the reservoir to be considered. The scale of the heterogeneity, and the resolution needed to detect or measure it, will dictate the appropriate tool (Fig. 2 ).

Megascale heterogeneities define the boundaries (size and shape) and control the reserves and primary recovery of the reservoir. Data required for reserve calculation and primary recovery estimation are those used in characterizing these megascale heterogeneities and are primarily in the domain of geophysical analysis. At this scale, reservoir interconnectedness and reservoir boundaries are the important controls (Van De Graaff and Ealey, 1989). Macro- or reservoir-scale heterogeneities form internal barriers to flow that affect interwell fluid communication and injection/production behavior.

Effective tools for measuring macroscale data are scarce. Lateral discontinuities are usually estimated by well tests or geological correlations. Mesoscale heterogeneities are those that can be identified within a genetic sandbody and include bed boundaries and stratification types. Data acquisition to delineate heterogeneities in the mesoscale is concentrated around core-calibrated downhole (e.g., well $\log$ ) measurements, and could play a role in linking reservoir data from the micro- to macroscale to create a unified model to properly characterize reservoir anisotropy and heterogeneities (Worthington, 1991). Mesoscale flow barriers can influence fluid flow and anisotropy in the macroscale, depending upon the distribution and size of the feature (Saleri, et al., 1991). Microscale heterogeneity data are typically measured by routine core and petrographic analyses. These data are fully utilized in generating depositional and diagenetic models. Microscale heterogeneities promote trapping of oil in waterflooding; the release of this trapped oil is one of the objectives of many of the EOR processes (Melrose and Brandner, 1974)

A number of recent studies (Honarpour, et al., 1988; Saleri, et al., 1991; Van De Graaf and Ealey, 1989) illustrated that the dominating heterogeneities are of different scale at different field development stages. As these stages progress from primary to secondary to tertiary recovery, the scale of heterogeneity that needs to be considered becomes finer and finer. More of the finerscale data are needed if application of an EOR process is contemplated. Selection of the EOR process will depend upon the reservoir setting and the heterogeneities found in the reservoir (Venuto, 1989; National Petroleum Council, 1984). However, the amount of microscale data required is also dependent upon the process applied and the simplifying assumptions used in modeling the reservoir. Ringrose, et al., (1991), showed that a less detailed reservoir description is required in a layer-cake model with viscous stable displacement. In waterflooding, even if the most influential heterogeneities are of the macro- and mega-scales, the ultimate recovery efficiency is still affected by mesoscopic heterogeneities such as crossbedding (Kortekaas, 1985).

The amount and type of data needed for reservoir characterization is determined by the recovery process applied (Ringrose, et al,, 1991). Therefore, the usefulness of a piece of data will depend upon the stage of field development. Timeliness is an important issue in data acquisition. The opportunity for collecting a number of critical data (e.g., PVT, brine analysis, initial pressure, etc.) once lost cannot be regained (Saleri, et al. 1991). It is therefore important to have the foresight and to plan the project before anticipated field development; to determine data needs in designing waterflooding and EOR processes (Raza, 1990; Venuto, 1989); and to acquire data as the opportunities arise. Geochemical alterations induced during reservoir development for example, can significantly change a number of original reservoir properties (Szpakiewicz, et al., 1987). The man-induced alterations are rarely recorded and monitored in a systernatic way before implementation of tertiary recovery processes.

There is never enough data to completely characterize a reservoir; therefore, a stochastic approach is often needed (Weber and van Geuns, 1990). Stochastic techniques are necessary because of the: (1) incomplete information about dimensions, internal architecture, and rock-property variability on all scales; (2) complex spatial disposition of reservoir building blocks or facies; (3) difficult-tocapture rock-property variability and spatial distribution; (4) unknown relationships between property value and volume of rock for averaging to grid block scale volumes; (5) the relative abundance of static (point values along the well for (permeability, porosity and water saturation) over dynamic (time dependent effects, how the rock architecture affects recovery) reservoir data.

A data acquisition program is dictated by the geologic and geographic settings, size of the anticipated recoverable resources, reservoir properties, and other reservoir specific attributes.

\section{Data Sources And Measurement Tools}

\section{Reservoir Data}

The two basic sources of data for reservoir characterization are from specific reservoir data and information from analogous reservoirs, outcrops, and 


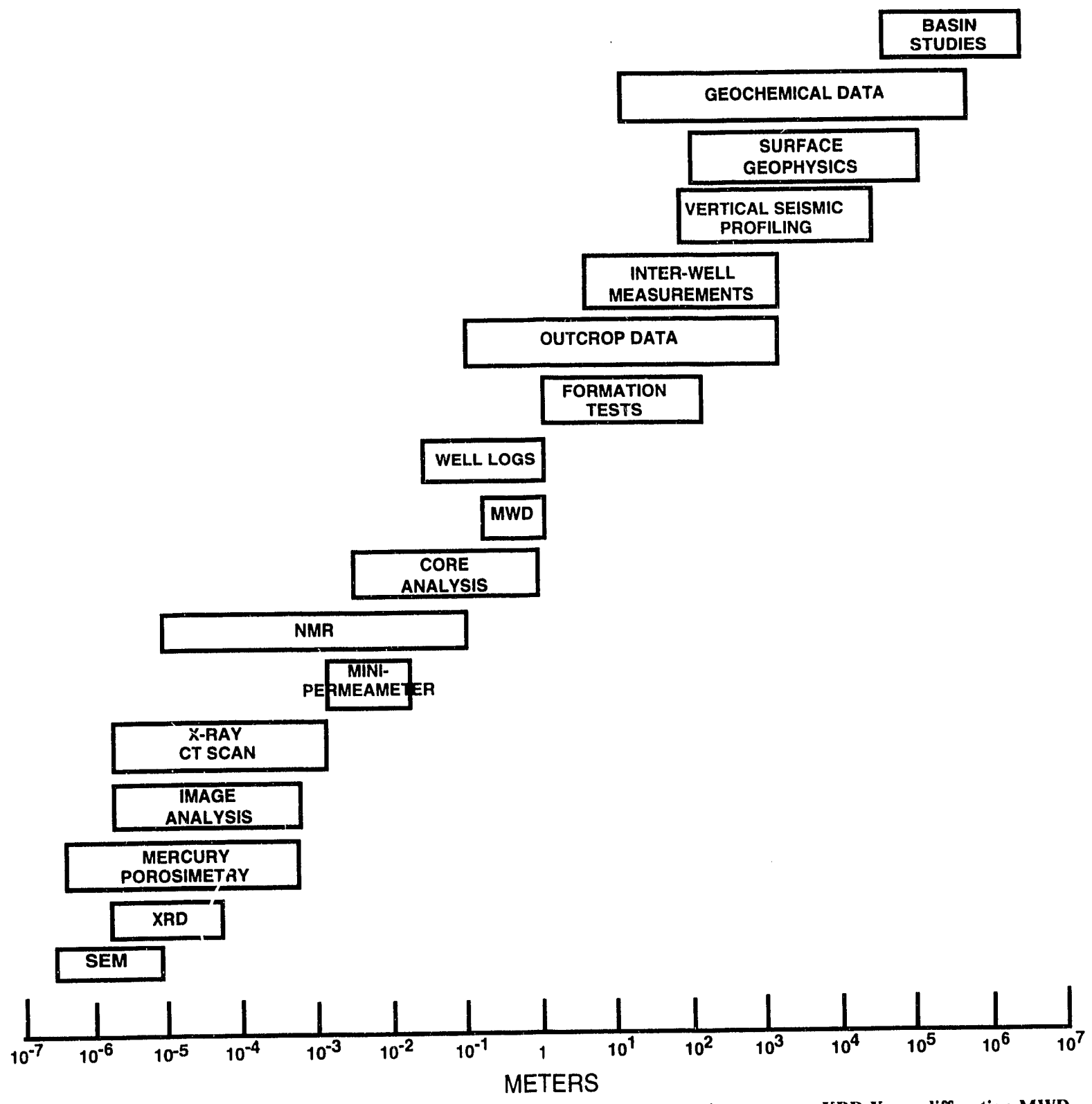

Tip 2 Scalion MWDFig. 2 Scales of measurement tools expressed the resolution of the tool. Upper values are the typical or maximum sample size. (modified from Worthington, 1991).

modern environments. Reservoir data can be broadly divided into three categories: (1) rock properties (the container), (2) fluid properties (the contents), and (3) rock/fluid interactions. Although most reservoir characterization efforts have been applied to the characterization of rock properties, fluid characteristics including geochemistry and heterogeneity of reservoir container), (2) fluid properties (the contents), and (3) rock/fluid interactions. Although most reservoir characterization efforts have been applied to the characterization of rock properties, fluid characteristics including geochemistry and heterogeneity of reservoir fluids and subsequent rock/fluid interaction are essential to the development of accurate reservoir models.
Reservoir characterization requires data on a range of scales from basin to field-scale information $(\mathrm{km})$ to poresize information (microns). Field-scale information establishes the spatial framework and the general architecture of the reservoir for describing and predicting smaller-scale reservoir geometries and heterogeneities, along with their associated petrophysical and fluid-ilow properties. Examples of the types of information obtained from field-scale description are: (1) compartmentalization of the reservoir into more than one producing zone or unit; (2) the position, geometry, and connectivity of the facies or reservoir units; (3) the evaluation of the spatial distribution of lithologic heterogeneities that comprise barriers, baffles, and high 
permeability "thief" zones; and (4) the relationship of the lithologic units to hydraulic units so that the fluid-flow pathways can be identified.

Mesoscopic scale information looks at the variations of properties within the facies or reservoir units. Core-log calibrations are used to: (1) establish the representativeness and compatibility of the measured limit; (2) integrate downhole measurements with data from pore studies, core analysis, and geophysical surveys through inter-scale reconciliation; (3) identify reservoir units with similar petrophysical properties; and (4) relate and reconcile petrophysical interpretations with geochemical, sedimentological, stratigraphic, and structural information.

Microscopic or pore-scale information that affects fluid flow in reservoir rocks includes the pore size, pore throat size, surface roughness, grain size, sorting mineralogy and clay content. The major controls on these features are the sediment source (provenance) and the subsequent diagenetic processes of compaction, cementation, and dissolution.

\section{Diagenesis}

The knowledge of diagenetic features and processes are important for drilling, completion, and stimulation applications, log analysis, and estimation of injectionfluid/rock interaction processes as well as pore geometries and pore-throat types, and must be taken into account for each stage of production.

Currently, the capability to predict the types, spatial distribution, and effects of diagenetic products is not well developed. Techniques available for describing the diagenetic phases found within reservoir rocks include scanning electron microscopy, $\mathrm{X}$-ray diffraction, electron microprobe microanalysis, and vitirinite reflectance. Other techniques that are less well known, and whose utility is less well understood are fluorescence microscopy, cathodluminescence, fluid inclusion analysis, atomic absorption, and stable and radiogenic isotope analysis for mineral samples.

Predictive diagenetic models are constructed by integrating information on different scales from multiple, diverse analytical techniques. The models predict the sequence and spatial distribution of diagenetic phases within specific reservoir strata, on the interwell- to fieldscale. The predictive diagenetic models require processbased, basin-wide studies to provide basic regional information about diagenetic cycling, recharge and fluid flow, heat flow, subsidence rates, open vs. closed systems, tectonic complications, basic mineralogy, and rock-water interactions. The key to understanding the importance of diagenesis to reservoir characterization is the interpretation and integration of diagenetic processes from a number of relatively independent analytical techniques.

\section{Fluid Characteristics Composition and PVT Data}

The composition and properties of reservoir fluids (formation water, oil, and gases) are essential for reservoir characterization. Undesirable geochemical effects commonly found in reservoirs such as formation damage, plugging of slotted intervals, scaling and corrosion of casing and production pipe, channeling of injected chemicals, and slug degradation may result from incomplete fluid characterization. Few studies have documented the lateral and vertical distribution of the different geochemical characteristics in a reservoir. Analytical techniques for analyzing reservoir fluids are gas chromatography, mass spectrometric analysis, and ratios of various organic fractions such as pristane/phytane ratios.

Pressure-volume-temperature (PVT) measurement procedures for reservoir fluids have been well-established in the laboratory. PVT measurements include solutiongas ratio, viscosity, formation volume factor, and fluid density at various pressures. Several empirical correlations (Beal, 1946; Dodson and Standing, 1944) have also been developed to estimate PVT values of the oil system based on the oil gravity.

The important constituents in produced water are dissolved ions, such as $\mathrm{Na}^{+}, \mathrm{Ca}^{++}, \mathrm{Mg}^{++}, \mathrm{Cl}^{-}, \mathrm{CO}_{3}{ }^{-}$, $\mathrm{SO}_{4}^{--}$, etc. Similar to PVT measurements, formation water analysis methods are well established in the laboratory. Among various formation water analysis results, the variation in the amount of total dissolved solids (TDS) in the water is critical to the interpretation of water saturation in the formation using resistivity log data. Study of the formation water chemistry in Patrick Draw field shows that TDS can change over three-fold within a distance of 1 mile. Erroneous interpretations of water saturations might be obtained due to an assumption of constant salinity in the field. In addition, formation water samples must be taken early in the life of a reservoir to obtain representative samples.

\section{Petrophysical Data}

Measurements of petrophysical (static) properties are obtained by core analysis, well logs, and downhole seismic techniques. Dynamic reservoir properties are obtained by core flooding and accompanied by image analysis of pore systems, well testing, and analysis of injection/production data. Recent advances in well log and seismic techniques provide increased resolution and allow pore geometry modeling with imaging tools.

\section{Porosity}

Porosity values are used for determining rock void space and possible volumes of hydrocarbon. Void spaces provide the storage capacity for hydrocarbons. In addition, porosity values are necessary for calculating 
water saturation in reservoir rock. Porosity values can be measured by core analysis or well logging.

Core analysis is a direct method that measures rock porosity in the laboratory and is based on principles such as gas expansion or summation of saturations. Most methods have been designed for small samples. All methods commonly used to determine porosity yield results within \pm 0.5 porosity per cent (Dotson, et al., 1951). Since the error of porosity measurements is inversely proportional to the total sample volume, it is recommended that samples be as large as possible.

Porosity can also be determined indirectly from logging methods such as formation density logs, neutron logs, and acoustic logs. Neutron logs respond to the amount of formation hydrogen, which is an index to porosity. Although water and oil are substantially the same in hydrogen content, gas is considerably lower. Thus, neutron logs are able to distinguish between liquid- and gas-saturated intervals. In contrast to neutron logs, density logs measure the electrons density of the formation or the density of formation rock using gamma rays. Porosity values are then calculated from measured bulk density values. Since neutron logs underestimate porosity values and density logs overestimate them for rock containing gas, these two logs are often used together for measuring rock porosity.

Logging techniques have the advantage of averaging larger volumes of rock than core analysis. When calibrated with core data, they should provide porosity values in the same range of accuracy as core analysis.

Cross-hole tomographic methods, although currently expensive, allow the identification of high-porosity zones. Three-dimensional high resolution seismic has the resolution to allow mapping of lithology and porosity at depth on a gross scale.

\section{Permeability}

Permeability is a measure of the ability of fluid to flow within the interconnected pore network of a porous medium. Reservoir flow rates, including oil production rates, are proportional to the permeability wise of reservoir rock. On the other hand, rock permeability determines the pressure drop required to produce or inject fluid from an existing reservoir at a desired rate.

Core analysis is the primary source for obtaining rock permeability values. In the proper development of reservoirs, it is customary to core selected wells throughout the productive area, measuring the permeability and porosity on each foot of core recovered. The cores are normally cleaned of residual fluids and dried prior to conducting permeability measurements. The permeameter measures the flow rate of gas and the pressure drop across the core plug to determine permeability using Darcy's law.

Factors affecting permeability meas:rements inclicte the gas slippage at low pressures and the non-Darcy flow at high flow rates. At high flow velocities there is additional contribution to the pressure gradient that results in an underestimation of the permeability value. To account for this effect, Darcy's law needs to be modified according to the Forcheimer equation (Dake, 1978). This effect is important in very high-velocity flows as would be encountered in some gas wells. At the other extreme of low pressure condition, the Klinkenberg effect results in increased values of permeability (Klinkenberg, 1941). Frequently, the Klinkenberg effect is extracted from experimental measurements by plotting apparent permeability vs. inverse mean pressure. The intercept of such a plot is the true permeability.

One alternative way of measuring permeability is by pressure transient testing. In contrast to measuring the permeability values of core plugs in the laboratory', the pressure transient testing technique (Earlougher, 1977) measures the permeability of reservoir rock around a well from pressure buildup, draw down, injectivity, and falloft tests, or the interwell permeability from pressure interference and pulse tests. Well tests determine the "effective" permeability of a large volume of the reservoir rock within the drainage radius. Although it measures the real response of a formation, pressure transient testing is not useful for delineating permeability distribution in a wellbore or reservoir.

Vertical permeability values are important in some flow situations such as coning, gravity drainage, and cross flow between sand layers as well as in the effectiveness of the polymer-gel method of profile modification. Vertical permeability values can be measured on core plugs. Well test data such as vertical interference and pulse tests can also be used to estimate these values.

The direct determination of permeability in the laboratory uses reservoir cores that represent only a small part of the reservoir. Hence, indirect methods or empirical correlations are used to estimate reservoir permeability from porosity values. For field studies, a correlation of the logarithm of permeability vs. porosity values is commonly used for reservoirs belonging to the same formation. Other permeability estimation approaches (Monicard, 1984) include methods based on log measurements, pore distributions, and internal surface areas. All of these indirect correlation formulas are very approximate and must be used with caution.

Promising advanced methods for downhole permeability estimation include the analysis of Stoneley waves from sonic wave form logs (Cheruvier and Winkler, 1987). The development of proton magnetic resonance tools that are not excessively affected by the wellbore environment (Jackson, 1984) are being investigated for more meaningful estimates of pore (surface) characteristics for better permeability prediction in situ.

\section{Fluid Saturation}

Hydrocarbon saturation values are used to define pay zones and determine the amount of oil in place. Fluid 
saturation in rock can be determined using core analysis or logging methods.

Core analysis is a direct method for measuring oil saturation in the laboratory. Oil and water saturation can be determined from cores by distillation at vacuum or atmospheric pressure conditions. Water content can also be determined by the solvent extraction (or Dean-Stark) method. Based on core-retrieval tools, core analysis for saturation measurements can be classified by three categories: conventional, pressure, and sponge coring.

Oil saturation values determined by conventional core analysis are substantially less than in situ values obtained from logging methods. The most severe change in oil saturation is caused by expulsion and associated volume reduction of oil in the core as pressure decreases when the core is lifted to the surface. Attempts have been made to correct oil-saturation measurements obtained by conventional coring analysis (Luffel and Randall, 1960) but with unreliable results.

Pressure coring solves expulsion and shrinkage problems by maintaining the core specimen at bottomhole pressure until the core fluids can be immobilized by freezing. Experience has shown excellent accuracy in oil saturation measurement from pressure coring (Sattler, 1984). Reservoirs with pressures from several hundred to more than 6,000 psi have been successfully cored using this process. Special techniques for analyzing cores recovered by pressure coring methods have been developed (Carlisle, et al., 1983).

Sponge coring uses a sponge-sleeve modification to a conventional core barrel. The sponge sleeve is made of a porous, oil-wet, polyurethane sponge. The oil bleeding from the core is collected in the sponge and reconstituted back into the core porosity to correct the oil saturation for bleeding. The sponge-coring technique reportedly provides oil-saturation measurements approximating those determined by pressure coring but at a cost cioser to that of conventional coring (Park, 1984).

Logging methods are widely used for obtaining oil saturation profiles for field evaluations. The resistivity $\log$ is used because of its low cost and relatively deep zone of investigation from the wellbore. The resistivity measurement that allows computation of water saturation is determined by Archie's equation. Formation parameters such as water salinity, shale content, porosity, cementation factor, and saturation exponent, need to be calibrated carefully to provide reliable saturation estimations from resistivity logs. Resistivity logs are limited to open holes. Other open hole logs include nuclear magnetic log (NML), electromagnetic propagation tool (EPT), and dielectric constant log.

For EOR projects, evaluation of residual oil saturation (ROS) after waterflooding generally requires greater accuracy than oil saturation measurements for primary production (Chang, et al., 1988). One way to reduce uncertainties in resistivity logging is to use the loginject-log (LIL) method (Murphy, et al., 1973). In LIL, the oil is removed by injecting chemicals after the formation is logged. A slug of formation water is then injected and the formation is logged for resistivity again. With the knowledge of saturation exponent, ROS can be determined. The LIL technique can improve ROS measurements of resistivity log from an accuracy of \pm 10 to \pm 3 saturation units (s.u.).

To measure fluid saturation behind casing, cased-hole logs such as pulsed neutron capture (PNC) $\log$ and carbon/oxygen log are valuable tools. The PNC log measures the capture cross section of the formation, which is the sum of the component cross sections of the rock matrix and the fluids within the pores of the rock. The LIL technique can be extended to PNC log for measuring ROS through casing. The PNC-LIL method (Richardson, et al., 1973) enhances ROS measurements by injecting a contrasting-salinity water to eliminate the need of capture cross-section measurements of rock matrix and residual oil. The PNC-LIL method has good $( \pm 4$ s.u.) to excellent ( \pm 2 s.u.) accuracy in determining ROS behind casing.

Other advanced logging techniques include the laminated sand analysis (LSA) tool, that has increased resolution and enables the detection of hydrocarbons in thinly bedded intervals; the geochemical logging tool (GLT); and the nuclear magnetic $\log$ (NML). The geochemical tool uses nuclear measurements to infer a geochemical signature in terms of elemental abundance within the reservoir rock. The elemental concentrations are then used to predict mineralogy (Hertzog, et al., 1987).

\section{Pay Thickness}

The thickness of pay zones is one of the parameters that determines total oil in a formation. The sands with permeability and oil saturation values above the cutoff value, are considered to be the pay zone. The location and the thickness of pay zones can be determined from reservoir cores or well logs. A net isopach map, which shows lines connecting points of equal net pay thickness, is used for calculating the oil reserves in a reservoir.

\section{Reservoir Boundary}

The boundary of an oil reservoir is typically defined during development. In addition to new well drilling, locations of fluid contacts, such as oil-water and gas-oil contacts, can be calculated using data of fluid pressure regimes.

At a static interface of the oil-water contact, the pressure in the oil and water must be equal. But hydrocarbon pressure regimes are different in that the oil and gas densities are less than that of water and, consequently, the pressure gradients of oil and gas are smaller. Thus, in a well drilling through a sealing shale on the crest of the structure, there will be a sharp pressure kick. The magnitude of the pressure discontinuity on drilling into a hydrocarbon reservoirs can be used to 
calculate the vertical distance between the drilling point and the hydrocarbon water contact (Dake, 1978). The oilwater or gas-water contact can then be determined if the formation dip and fluid density data are available.

Another powerful tool for delineating reservoir boundaries is seismic data. The 3-D seismic data identifies the location of reservoir boundaries and structure (Ruijtenberg, et al., 1990).

\section{Faults}

Faults are vertically displaced fractures and are typically barriers to fluid flow by either disconnecting the reservoir or by the low permeability of the gouge (clay-sized particles ground by fault movement) occurring in the fault. Linear discontinuities such as sealing faults can be detected by well testing methods. As a draw down or buildup test proceeds from a well near a linear fault, the semilog plot of pressure vs. time will have a second straight-line portion with a slope double that of the initial straight line (Earlougher, 1977). The test time at the intersection of two straight lines is used to calculate the distance of a linear fault from a test well. However, the simple occurrence of a doubling of slope in a transient test can be caused by wellbore storage effects. Thus, it is important to construct a log-log plot of transient test data to determine when wellbore storage effects are no longer important.

Hall plots of water injection pressures can also provide information about nearby faults/barriers or pinchouts of permeable sands (Honarpour and Tomutsa, 1990). A high slope value in a Hall plot after the fillup of void space in a reservoir may be caused by nearby faults or barriers when wellbore skin is taken into account. The closer the fault or the more nearby faults, are encountered, the sharper is the slope of the Hall plot. Hall plots were also used to infer fault locations in Arch Unit, Patrick Draw field.

\section{Fractures}

Fractures often occur in orthogonal networks, and may be sealing or conductive, depending on the direction and magnitude of in situ stresses (Teufel and Lorenz, 1992) and the degree of "healing" or cementation of the fracture plane. Fractures can be identified from core examination, logging techniques, pressure transient testing, tracer tests and analysis of waterflood front movements.

Fracture density is recognized and measured from cores only in exceptional circumstances when core recovery is good and the fracture system has a suitable density and orientation. Core study is of inportance for determining fracture type, age, surface characteristics, and conductivity.

Fractures are identifiable on logs when hole conditions and matrix responses are favorable. As with core analysis, the sample or the borehole is very small compared to the reservoir as a whole, thus circumstances have to be ideal before fracture orientation and fracture density can be assessed.

A pressure buildup curve from a fractured reservoir displays two parallel semilog straight-lines during the shut-in time (Earlougher, 1977). The pressure buildup of a fractured reservoir for early time is the same as that in a homogeneous reservoir. As a nore rapid stabilization of pressure in the more permeable fractured system occurs, the pressure buildup lags. As inflow from the rock matrix system progresses, the pressure buildup assumes a trend parallel to that of early time. The slope of either straight line indicates the total system permeabilitythickness product. The vertical distance between the two semilog straight lines may be used to estimate the ratio of the porosity-compressibility product in the fracture to that for total system.

Interwell tracer testing is a useful tool for examining the fracture system of reservoirs. Interwell tracer testing consists of the injection of tracers in injection wells and the subsequent sampling of production wells for tracer concentration. The production history of tracers is used to determine the existence and directions of fractures or high-permeability channels in the reservoir. Most tracer tests have been used, in a rather qualitative manner, to determine whether or not communication or barriers exist between wells, or to find out preferential flow directions in a reservoir. For a quantitative interpretation, reservoir simulators are frequently used in tracer tests for identifying reservoir fractures or barriers. The tracers used include radioactive gas, chemical, and dye tracers or organic compounds tagged with stable isotopes.

In the absence of tracer tests, the waterflood front movement can be traced using resistivity logs. Analysis of the waterflood front movement in the pilot area of Bell Creek field indicated that the faults oriented in the northeast-southwest direction channeled injected water, while the faults oriented northwest-southeast retarded the waterfront movement (Honarpour, et al., 1988).

\section{Relative Permeability}

Relative permeability is one of the most important input parameters for reservoir simulation and recovery prediction; the reliability of recovery forecast depends critically on the accuracy of this parameter. It is also one of the most abused parameters for reservoir modeling in that its value is often adjusted to history match production data. Accurate relative permeability data are difficult to obtain because they require careful execution of the procedures established for relative permeability measurement (Heaviside, 1991). For reliable measurement, the native wettability of the core has to be maintained, and the saturation history of the recovery process has to be simulated.

Two-phase relative permeability (oil/water or oil/gas) can be measured in the laboratory using steady-state (Hassler, 1944) or unsteady-state (Johnson, et al., 1959) methods. Relative permeabilities obtained unter steady- 
state conditions take more time than those from unsteadystate conditions.

The importance of measuring in situ fluid saturation at reservoir conditions during relative permeability measurements was emphasized by Honarpour and Mahmood (1988) and Honarpour and Maloney (1990). Measurement of relative permeability from steady-state measurement is tedious and usually involves judgment based on experience of the analyst. Sometimes simplifying assumptions are made that compromise the accuracy of the results.

Three-phase relative permeability measurements are even more difficult than oil/water or gas/oil two-phase relative permeability. The results of Oak (1990) and Maloney, et al., (1990) provide some of the most accurate three-phase relative permeability data available in the literature. Stone's (1970) model is commonly used to predict three-phase relative permeability from two-phase data; however the accuracy of this method has been questioned. (Oak, 1990).

\section{Capillary Pressure}

Capillary pressure is the difference in pressure across the interface between wetting and nonwetting fluids such as water and oil. The capillary pressure affects the twophase flow in the rock, especially for the tight rock that capillary pressure could result in a significant contribution of fluid flow through the imbibition of the wetting fluid.

There are five recognized methods (Frick, 1962) for measuring capillary pressure on sinall core samples: (1) the desaturation or displacement process through a porous diaphragm or membrane (restored-state method), (2) the centrifuge method (USBM) (3) the mercury injection method, (4) the dynamic-capillary-pressure method, and (5) the evaporation method.

The diaphragm method appears to be superior in that oil and water are used and thus more nearly approaches actual wetting conditions. Hence, the diaphragm method is used as the standard against all other methods. The disadvantage of this method is the 3 to 4 weeks measurement time involved. The mercury injection method is rapid and precise but destroys the tested core. However, this method can provide additional information on pore morphology. The centrifuge method is useful for obtaining a point corresponding to a high capillary pressure.

In contrast to direct measurements, a capillary pressure curve can be derived from well log data by plotting water saturation values vs. gas-oil or oil-water contact. The distance from the oil-water contact is then converted into a capillary pressure.

\section{Pore Structure}

Modeling of fluid flow and displarenitent in porous media requires information about pore structure, pore size distribution, rock mineralogy, and internal rock surface area. Analysis of X-ray, NMR, and thin section analyses are often used to obtain that information.

Recent advances in computerized quantitative image analysis (Ruzyla, 1986) have made possible the rapid and accurate measurement of rock microstructure. The optical image of rock thin sections or polished sections is scanned by a video camera, converted to digital form, stored, and processed on a microcomputer. Such an image analyzer is configured for measurements of pore sizes, pore-shape distributions, specific surface area, and porosity percentage.

Computed tomography (CT) is a radiological imaging technique (Wellington and Vinegar, 1987; Tomutsa, et al., 1988; Tomutsa, et al., 1990) that measures 3-D distributions of density and porosity, characterizes fractures and drilling mud invasion, and quantifies complex mineralogies. CT scanners generate crosssectional image slices through the object by revolving an $\mathrm{X}$-ray tube around the object and obtaining projections at many different angles. From a set of these projections, a cross-sectional image is reconstructed by a backprojection algorithm in the scanner's computer. The cross-sectional image of attenuation coefficients is displayed on a monitor. The beauty of CT is that attenuation differences as small as $0.1 \%$ can be measured accurately within an interior region of $2 \mathrm{~mm}^{2}$ or less.

Nuclear magnetic resonance (NMR) imaging techniques measure the distribution, flow, and mobility behavior of proton-containing liquids (Mahmood, et al., 1990; Blackband, et al., 1986). Discrimination of light crude oil and water is demonstrated by proton chemical shift differences. NMR imaging is inherently more informative than radiographic techniques and much less hazardous. The potential of the NMR imaging technique for core analysis will depend on its instrumental development (Doughty and Tomutsa, 1992).

\section{Production/Injection and Pressure Data}

Analyses of injection/prorluction and reservoir pressure data are effective in measuring the dynamic fluid flow characteristics of a reservoir and to evaluate reservoir performance. These data provide needed information to refine reservoir models based on static rock and fluid measurements. A continuous and consistent effort in the acquisition and organization of production/injection data should be made throughout the life of the reservoir.

Recently, researchers have extended the application of these tools to reservoir characterization. By production history matching (Honarpour, et al., 1988) and by mapping the waterfront advancements during the secondary production (based on watercut production data), and comparing them with front advancements generated by simulation, one can, in certain cases, spot both barriers to flow as well as high permeability thick zones. The existence of production history, combined with simulation, can be very useful in reservoir 
characterization. By carefully monitoring the pressure and injection flow rates, one can construct Hall plots whose slopes indicate the permeability of the regions surrounding the injection wells (Honarpour and Tomutsa, 1990).

\section{Geophysics and Cross-hole Tomography}

Recent developments in seismic techniques have expanded their use to more detailed reservoir architecture imaging and also to interwell front movement monitoring. The main constraint to their extended application is the cost, the computer intensiveness and, often, insufficient resolution for facies definition. This constraint can be addressed by selecting the areas in which seismic data will be collected and making maximum use of the existing core and log data together with the available seismic data.

The seismic technique is highly desirable in planning developmental drilling and in secondary and enhanced oil recovery operations. With the greater number of recording channels, and the ability to record higher frequencies, it is now possible to obtain much greater resolution in subsurface imaging. In particular, 3-D seismic has been used to map complex fault patterns in great detail, information vitally important to the petroleum engineer, before planning any secondary or tertiary project that involves injection of expensive chemicals and fluids into the reservoir.

Vertical seismic profiling (VSP) data provide geological information in the interwell areas much like the 2-D seismic, but VSP data normally has higher resolution than the surface seismic, because in this method of survey the geophones are inside the borehole, close to the object being investigated by the wave field. Like 2-D surface seismic, however, VSP only provides information along a geological section. There are no practical depth limitations to any of these methods, but data resolution normally deteriorates with depth because of rapid attenuation of higher frequencies with depth.

Seismic data can be used to: (1) estimate rock and fluid properties; (2) monitor EOR process front movement; (3) estimate rock mechanical properties and locate faults; (4) construct accurate reservoir models.

Estimation of rock and fluid properties. Characteristics of seismic waves including amplitude, phase and interval velocity change between seismic events have been correlated with porosity, fluid type, lithology, net pay thickness, and other reservoir properties. The correlations usually require calibration by borehole data and well logs. The 3-D seismic data are commonly used in the productive Pleistocene trend of the offshore Gulf of Mexico to directly map gas saturation.

Seismic amplitude values have been directly transformed into product of porosity and thickness by geophysicists from Arco Oil and Gas Company in their North Slope, Prudhoe Bay oil field in Alaska (Robertson,
1989), and the method was used to map porosities in under drilled parts of the field. Seismic lithologic modeling has been successfully used in studying the variations in acoustic impedance and their associated implications on porosity across the Yaphour oil field in Abu Dhabi (Zake, et al., 1990).

Monitoring of EOR processes. In recent years, a number of seismic techniques have been used in monitoring movement of fluids in the reservoir during EOR processes. This flow monitoring is still in the experimental stage, but major advances are expected in the near future. The seismic technique will be particularly useful in monitoring EOR processes like steamflooding where the extreme temperature and pressure of the injected fluid create sufficient changes in acoustic impedance; and, consequently, the reflected seismic wavelet so that the movement of fluid can be detected on the seismic section.

Greaves and Fulp (1987) report successful monitoring of an in situ combustion project, while Pullin, et al., (1987) have described the imaging of fluid movement at the Athabasca tar sand thermal EOR project in Calgary, Canada.

Determination of rock mechanical properties and fractures. With the introduction of the threecomponent geophones in seismic surveys, it is now possible to record two horizontal components of shear waves (s-waves) along with the compressional, $\mathrm{p}$-waves measured in conventional surveys. Poisson's ratio of rock masses, estimated from the $\mathrm{p}$ and $\mathrm{s}$ wave data, provides information about mechanical strength of rocks. Since shear waves cannot propagate through fluids, they have been used in mapping fluid filled fractures. The ratio of compressional and shear waves has also been used in lithology identification because of the different propagation characteristics of $p$ and $s$ waves.

Tatham and Stoffa (1976), Ensley (1989), Nations (1974), and others have discussed how combined studies of $p$ and $s$ wave velocities can help in identifying lithologies and in determining fluid saturations. Davis and Lewis (1990) discuss how three-component geophone system can be used to study fracture density in a chalk reservoir and have demonstrated how the map of fracture density and connectedness is correlatable with production.

Integration of Seismic and Well Log Data With Geostatistics for Accurate Reservoir Description for Reservoir Simulation. The various recently developed geostatistical techniques can be integrated with Seismic and log data to provide reservoir data at grid points required for reservoir simulation. Doyen (1988) demonstrated the use of a geostatistical cokriging method with seismic transit time data to study the porosity variations in a channel-sand reservoir from the Taber-Turin area of Alberta, Canada. 


\section{Well Testing}

Transient well testing is an important diagnostic tool, especially for the definition of near-wellbore and interwell conditions. Transient well testing provides a reservoir description which is directly applicable for production and reservoir engineering calculations, where the values are directly measured and not inferred. Well tests sample a much larger volume than core-sampling and well logs, that only measure near wellbore properties. Well test data is an average of the properties over a volume of the reservoir that approaches the drainage volume of a well. Results are obtainer in a relatively short period of time and with minimal effort. Well testing was used extensively in the 1970's and 80's to detect interwell communication and diagnose near-wellbore conditions with great success. Recent advances in well testing (Ramey, 1990) include the use of log-time der ivative of the storage and skin solution with the Gringarten form of the storage-type curve to obtain a unique match with field data, computer aided interpretation, and better pressure and flow rate measuring gauges.

The well-to-well tracer test is another engineering technique used extensively in EOR field project reservoir characterization. This method can identify presence of barriers, channels, and flow trends between injection and production wells. Abbasxadeh-Dehghani and Brigham (1984) and Brigham and Abbasxadeh-Dehghani (1987) developed the methodology for the application of tracer techniques in reservoir characterization and in developing a quantitative model for a heterogeneous reservoir. The methodology was successful in describing and quantifying areal and vertical heterogeneity (Ohno, et al., 1985, Singhal, et al., 1989). Allison, et al., (1991) extended this technique to describe reservoir heterogeneity and residual oil saturation distribution in the reservoir. The advantage of multiple tracers from a single injection well was clearly demonstrated in their work. This method provides a powerful tool for determining residual oil saturation distribution, which is one of the most important-if not the most important-parameter that determines the success or failure of an EOR project.

A limitation of tracer tests (both single well and wellto-well) is that the injected aqueous solution tends to flow through water saturated flow paths, which biases the result toward water-flow pore volume. In addition, in well-to-well tracer tests, the interwell flow barrier is a function of permeability and relative permeability (a function of saturation, lithology, and wettability). Without additional information on the lithology, pore size distribution, and wetting behavior of the barrier, the oil saturation and permeability calculated from a tracer test will not be unique. It is therefore important to incorporate geologic information (depositional and diagenetic models) into tracer test analysis.

\section{Analog and Regional Dato}

\section{Outcrop Information}

Outcrop exposures of reservoir rocks provide laterally continuous sampling of rock characteristics and provide lateral information on scales not available from reservoir data. Outcrop studies can be a valuable, low-cost source of high quality geological data. In the last decade, numerous papers have presented the results of quantitative outcrop studies, including both dimensions and geometries of sandbodies (Lowry and Raheim, 1991) and permeability and porosity measurements (Tomutsa, et al., 1986; Miall, 1988; Goggin and Chandler, 1989). These data will help define reservoir geometry, compartmentalization, rock type distributions, e.g., shale length distributions, (Haldorsen and Lake, 1982, Haldorsen and Chang, 1985) faulting, fracturing, and the spatial distribution of permeability and porosity. These data also will help define the scale at which further data should be acquired in the reservoir studied, as well as the optimum spacing for primary, secondary, and tertiary recovery. The constraints in utilizing outcrop data are: (1) the availability and accessibility of outcrops analogous to the reservoir; (2) the time required for preliminary reconnaissance work to identify analogous outcrops; (3) differences in facies architecture, diagenetic imprint, tectonic structure, etc., between outcrops and reservoir; and (4) limited experience in the application of outcrop data to reservoir model construction.

Widespread use of outcrop information has resulted in the collection of greater amounts of quantitative geological information on facies geometry and dimensions. Permeability and porosity data have allowed the correlation of facies and rock types with petrophysical characteristics and the delineation of determining flow units. Further work on the degree to which outcrop information can be incorporated into reservoir models, and the methods to do so, will greatly enhance our ability to develop detailed and correct reservoir models. Additional detailed outcrop studies are needed to develop large data bases from which statistically significant characteristics for particular deposystems can be determinet Finer subdivisions within depositional models are needed to incorporate first order controls on depositional systems such as tectonic setting, rate of subsidence, rate of sediment supply, sediment source (grain size, mineralogy), and degree of compaction.

The limitation of applying information from analogous depositional systems to reservoir simulation models, however, results from the underlying assumption that the statistics of facies dimensions, frequencies of occurrence, and interconnectedness ratios of particular facies within particular depositional systems are transferable from one deposit to another. Although theoretically many reservoir properties may be transferable from one deposit to another 
(Fig. 3), it is not yet known how to assess the degree of similarity and the applicability of data from analog occurrences.

For example, the deposition of fluvial channel deposits, within different tectonic settings, may result in very different grain sizes, sorting, and channel geometries due to the effects of rates of tectonic movement, sea level, and sediment supply. The fluvial channelbelt sandstones deposited during conditions of low subsidence rate may form vertically and laterally interconnected, blanket-like reservoirs, in contrast to the isolated, stringer-like sandstone bodies formed during periods of higher subsidence rate (Cross, 1991). Assessment of these controls requires establishing a high-resolution time framework and placing the distributions of facies within that framework (Cross, 1991).

\section{Regional-scale Controls on Reservoir Architecture}

Most of the effort in reservoir characterization is focused on pore- to bedding-scale features in an attempt to describe and understand fluid flow through porous media. While this scale is vitally important to the development of displacement processes, the reservoir architecture controls the communication between wells and exerts a very strong influence on sweep and recovery efficiency. Given enough well control and data, the compartments can be identified deterministically and mapped. However, even if one can deterministically identify the compartments, many times, one cannot predict their presence or location without understanding the regional context and basin-scale controls. The following examples from the reservoirs studied at NIPER illustrate how the understanding of regional scale processes aid the prediction of the location, orientation, and density of reservoir heterogeneity.

\section{Location of Valley Fill Barriers}

Both Bell Creek and Patrick Draw fields contain fieldscale permeability barriers that compartmentalize the reservoirs and dictate well locations and patterns. After a number of wells have been drilled, cored, and logged, these barriers have been identified deterministically by information from production/injection data, identification of water/oil and gas/oil contacts, reservoir pressure changes during field exploitation, and core and log data. The identification of these features, however, does not necessarily mean that they can be interpreted, that their origin can be explained, and therefore that any predictive capabilities can be generated purely by their identification. For predictability, the origin (genesis) of the features must be understood, and to understand the origin of the features, regional or basin-scale studies must be applied.

The valley fill deposits in Bell Creek field are examples of such large-scale features that control communication within the reservoir. Northeasierly trending valley fill deposits consisting of low quality reservoir rock and shales dissect Bell Creek field into noncommunicating units with different oil/water contacts and reservoir pressure regimes. The paleovalley separating Unit A from Unit B is filled with shaley, silty sediments, has cut down about $35 \mathrm{ft}$, and is about 500-ft wide. (Szpakiewicz, et al., 1989). Well spacings, of 10 acres ( $660 \mathrm{ft}$ between wells) could miss these features. Other valley fill deposits can be up to 1 mile wide with similar depth, for example, the one that separates Ranch Creek from Unit $\mathrm{E}$ (Weimer, et al., 1982).

The barrier island sand and overlying valley fill deposits were formed by the complex interplay of sea level changes and basement fault movement (Weimer, 1984; Gustavson, et al., 1988; Martinsen, 1992). Structural movement on basement-controlled fault blocks appears to have controlled the distribution of the Muddy members, drainage incisement patterns (location of valley fill fluid flow barriers), present structure and heat flow, and possibly petroleum migration. Recurrent movement of basement fault blocks has controlled the origin and distribution of porous and permeable sandstones which now govern groundwater and hydrocarbon fluid flow.

The sequence of depositional events for the shoreline barrier sand in Unit A in Bell Creek field (Bell Creek sand) was as follows (Szpakiewicz, et al., 1989; Gustavson, et al., 1988, Weimer, 1984):

1. The Bell Creek shoreline barrier sandstone was deposited as a widespread regressive sandstone during a highstand of sea level (98-99 Ma).

2 . Recurrent basement fault movement (estimated at 20-40 ft) occurred along a NE trend which formed a structural and topographic high across Bell Creek field.

3. Sea level drop (97-98 Ma); area subaerially exposed. Valley cutting and erosion of portions or all of the Beil Creek sandstone occurred. A paleotopographic topographic high formed a drainage divide between two major S-SW flowing streams. The Bell Creek sandstone was removed where incisement exceeded approximately 40 $\mathrm{ft}$ but was preserved over the drainage divide and formed the Bell Creek field.

4. Transgression occurred during rising sea level and resulted in valley filling of fresh water fluvial deposits in the lower topographic areas and then brackish to marine, extuaring (bay), and tidal flat deposits. The successive younger deposition on topographically higher areas is referred to as coastal onlap.

5. Continued sea level rise and erosion occurred during transgression. Up to $20 \mathrm{ft}$ of sediment may have been removed, leaving the surface of erosion (TSEtransgressive surface of erosion).

6. Black marine shale (Shell Creek) deposited and preserved as water depth increased. 


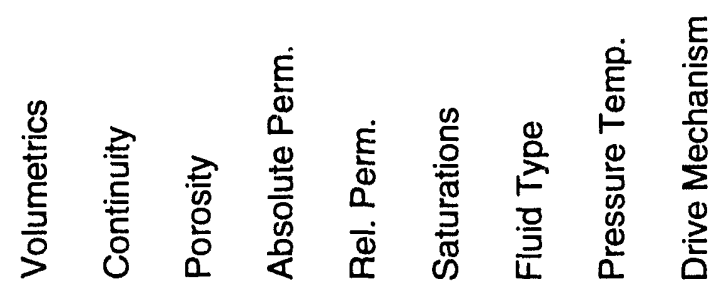

\begin{tabular}{|c|c|c|c|c|c|c|c|c|c|}
\hline External Geometry & 0 & 0 & & & & & & & \\
\hline Internal Geometry & & 0 & 0 & 0 & 0 & 0 & & & 0 \\
\hline $\begin{array}{l}\text { Pattern of Variation } \\
\text { (Quantitative Res. Properties) }\end{array}$ & $\otimes$ & 0 & 0 & 0 & 0 & 0 & & & \\
\hline $\begin{array}{l}\text { Absolute Values } \\
\text { (Quantitative Res. Properties) }\end{array}$ & $\otimes$ & $\otimes$ & $\otimes$ & $\otimes$ & $x$ & $\mathrm{x}$ & $x$ & $x$ & $\mathrm{x}$ \\
\hline \multicolumn{10}{|l|}{ DIAGENETIC CHARACTERISTICS } \\
\hline Compaction (including geopressure) & $x$ & & 0 & 0 & & & $x$ & 0 & \\
\hline Cementation & $x$ & $x$ & 0 & 0 & 0 & 0 & $x$ & 0 & \\
\hline Dissolution & $\mathrm{x}$ & $x$ & 0 & 0 & 0 & 0 & $x$ & 0 & \\
\hline Recrystallization & $\otimes$ & $\mathrm{x}$ & 0 & 0 & 0 & 0 & $x$ & 0 & \\
\hline \multicolumn{10}{|l|}{ TECTONIC CHARACTERISTICS } \\
\hline Folding & 0 & 0 & 0 & $\otimes$ & & 0 & 0 & & \\
\hline Faulting & 0 & 0 & $x$ & $x$ & & & $x$ & $\otimes$ & \\
\hline Fracturing & 0 & 0 & $x$ & $x$ & 0 & & $x$ & $\otimes$ & \\
\hline \multicolumn{10}{|l|}{ FLUID CHARACTERISTICS } \\
\hline Hydrocarbons & & & & 0 & 0 & $\mathrm{x}$ & $\mathrm{x}$ & 0 & \\
\hline Non-HC gases & & & $x$ & 0 & 0 & 0 & 0 & $x$ & $\underline{x}$ \\
\hline Formation Water & & $\otimes$ & 0 & 0 & 0 & $x$ & $\mathrm{x}$ & $\mathrm{x}$ & $\mathrm{X}$ \\
\hline Injected Fluids & 0 & & & 0 & $x$ & $x$ & $\mathrm{x}$ & $x$ & 0 \\
\hline $\begin{array}{l}0=\text { Property transferable } \\
\otimes=\text { Partially transferable (e.g. within a basin) } \\
X \text { = Pruperty not transferable }\end{array}$ & & & & & & & & & \\
\hline
\end{tabular}

Fig. 3 Degree of transferability of geological and reservoir properties between analogous deposits (modified from Lake, et al., 1991). 
7. Laramide or younger structural movement on basement fault blocks overprinted existing structures to give present structures. A higher heat flow along the north-east trending faults developed the hotspot anomaly at Bell Creek field (Weimer, 1984). Faults may also have controlled petroleum migration into the Bell Creek stratigraphic trap.

Knowledge of the relationship between basement faults and the development of valley fill deposits makes the prediction of orientation, location, and spacing of valley fill barriers possible. Regional structural data, including seismic lines and landsat images, may be used to assess the likelihood of the presence of these features in the reservoir of interest. Groundwater temperature surveys in the Minnelusa sandstone show higher than normal temperature anomalies that parallel structures of paleostructures. This suggests that temperature anomalies may occur where hydrothermal fluids migrate vertically along fracture systems (Weimer, et al., 1982); and that measurements of temperature, resistivity, and pressure surveys of pore fluids may aid in defining fracture systems associated with basement fault blocks.

Other examples of structure-controlled deposition presented by Jorgensen, et al., 1992 show how active tectonics control geometry and continuity of modern alluvial deposits in the Humbolt River in Nevada. Shurr (1992) also discusses the relationship of Cretaceous sand thickness and facies patterns to paleostructures and lineaments as identified from Landsat images in the Williston Basin, southwestern North Dakota.

\section{Regional Diagenetic Zone}

Kaolinite was found to be the dominant diagenetic clay in the tertiary incentive project (TIP) micellar polymer flood pilot area in Bell Creek field. Kaolinite and illite comprised as much as $15 \%$ by weight of the shoreline barrier sands (Honarpour, et al., 1989). The clay content caused two distinct permeability populations in the reservoir sand; and, in simulations, reduce waterflood oil recovery to $15 \%$ when clay contents approach $15 \%$ (Jackson, et al., 1991). Petrographic studies of samples from wells in the TIP area indicated early leaching and kaolinization (Honarpour, et al., 1989); however, the lateral extent of the kaolinite zone could not be determined until a wider view was obtained.

Regional studies found that kaolinite, siderite, and quartz resulted from widespread paleosoil development associated with the lowstand surface of erosion (sequence boundary) (Weimer, et al., 1988; Martinsen, 1992; Almon and Davies, 1979). The diagenetically formed kaolinite occur either as distinct layers or as cement in sandstones in a 3 to 5 - $\mathrm{ft}$ zone at the upper contact of the shoreline barrier sands and overlying valley fill deposits.

Knowledge of the relationship between the unconformity and kaolinite content provides an indication, in advance, that this clay is present throughout the reservoir, and that the EOR method selection and design must account for the presence of the clay.

Surdam and Heasler (1992) state that cementation along paleosols in the Muddy formation forms confining layers of 1-10 miles largest dimension. They show that these northeast-trending internal stratigraphic/diagenetic elements are low-permeability rocks in a single-phase flow system with finite leak rates but evolve digenetically into impermeable seals with discrete displacement pressures as the flow regime evolves into a multiple-phase fluid flow system. The appearance of hydrocarbons drives the transition from single-phase $\left(\mathrm{H}_{2} \mathrm{O}\right)$ to multiple-phase fluid flow; the hydrocarbons activate capillary seals and grossly increase displacement pressures in low-permeability rocks. When hydrocarbons saturate the compartment, the integrity of the bounding capillary seal is established. Although this is a regional phenomena, it can exert strong controls on the fluid distribution and oil saturation in a reservoir and effect resource calculations and, consequently, the development strategy.

\section{Faults}

Prior to NIPER's study, faulting and fractures were not identified in the available literature on Bell Creek, and only a few faults were reported in Patrick Draw field. Our study in Bell Creek identified a number faults with typical vertical displacements from 10 to $20 \mathrm{ft}$, and displacements greater than 40-ft were also identified (Szpakiewicz, et al., 1989). Analysis of production data and reservoir behavior indicated that faulting affected primary production by controlling the accumulation of oil in uplifted blocks. Effects on waterflooding front were that the set of closed fractures retarded waterflood front movement, while the open set caused faster waterflood front movement.

Construction of structural cross sections and analysis of seismic lines in Patrick Draw field has identified numerous, previously unreported faults with vertical displacements from 10 to $30 \mathrm{ft}$. (Schatzinger, et al., 1992). The full impact of the faults on production response in Patrick Draw field is currently being investigated; however, pressure depletion and formation water salinity anomalies coincide with a mapped fault and a prominent lineament, identified from Landsat images, suggesting compartmentalization of reservoir fluids and pressures.

In both Bell Creek and Patrick Draw fields, fault orientations are parallel to lineaments indicating that regional structural data, seismic lines, aerial photography, and landsat imagery could have been used as an indicator of the presence, density, and orientation of interwell-scale faults within the reservoir at early development stages. This type of data can be obtained with relatively little cost, when available published data and government maps and images are used, and can serve as a guide of what to look for and what features to expect in a reservoir. It should also be noted that the effect of faults and fractures may not be evident during primary production but may become 
apparent during the injection of fluids or with an an increase in reservoir pressures.

\section{Relationship Between Structure and Diagenesis}

Faults and fractures can create conduits for fluid flow that affect diagenetic processes. The relationship between diagenetic clay content and distance from faults was identified in Bell Creak tertiary incentive project (TIP) pilot area (Jackson, et al., 1991). Here, clay content increased away from faults suggesting that fluids along faults leached diagenetic clays. The distribution of clays in the TIP area exerted a strong control on permeability distribution and the recovery efficiency of the micellar-polymer EOR process (Jackson, et al., 1991). The knowledge of this relationship would help in locating wells and in designing the EOR process.

\section{Data Needs for EOR}

Data requirements are determined by the stage of field development and the scale of heterogeneities controlling the recovery process. During the discovery of a field the data requirements are minimal, with the important data being the reservoir boundaries and drive mechanisms. At this stage, seismic data are the most valuable and are usually available. As more y'ells are drilled and produced, additional core, $\log$, pressure, and production data become available to aid in location of additional wells and for designing waterflooding operations. With the development of waterflooding and smaller well spacing, a wealth of data becomes available: injection and production, pressure, salinity (if injection water is different from formation brine), and again core and $\log$ data. These data are invaluable in characterizing the smaller scale heterogeneities in the reservoir and assist in the development of a reservoir model for designing EOR processes.

The data requirements for EOR are more demanding and include all the data required for a proper waterflooding design and process-specific data. To minimize the volume of expensive chemicals injected, finer scale heterogeneities need to be defined to prevent these injectants being lost in the process (Table 1). At the stage when EOR is being considered, sufficient data should be available to define the reservoir volume (thickness and porosity) the residual oil saturation (ROS), and permeability. Other properties required are lithology, interwell connectivity, competency of layers bounding the reservoir, and fluid properties (oil, water, and gas saturations and composition). The information is required to determine: (1) if there is sufficient remaining oil to warrant the application of EOR; (2) that the injected EOR fluid will not flow out of formation due to incompetent boundaries; and (3) that the formation can sustain high enough injection rates to ensure economic production. These data are also required to apply the published screening criteria (National Petroleum Council, 1984) and to select EOR processes.
In an analysis of 84 previous EOR projects, Tham, et al., (1991) classified the 149 identified technical constraints to the success of these projects into 13 categories (Table 2). Eighty-nine of the 149 constraints can be removed (or partially remedied) using the appropriate remediation or recovery method. Selection of the best method requires enough reservoir data to identify and quantify the problems.

Of all these constraints listed in Table 2, one of the most prevalent is the loss of fluid out of formation. This is due to one of the following factors: (1) incompetent bounding layers (Bae and Syed, 1988), (2) presence of faults or fractures (Anthony, et al., 1981), or (3) pressure parting induced by injecting fluids (Lorenz, et al., 1984). Tracers, injection, and geologic data can detect the presence of these heterogeneities and prevent project failure due to these problems.

It is well known that EOR processes should be selected to take advantage of the unique characteristic of a reservoir (Venuto, 1989), and it is also known that each EOR process has its specific data requirements for reservoir characterization. Timely acquisition of the right data for use in screening, planning, and designing an EOR process can increase the success rate of the project. A discussion of the data requirements for the different EOR processes is given below.

\section{Chemical EOR}

In chemical EOR, surfactant and/or alkali are injected to reduce crude oil-brine interfacial tension, and polymer is injected to improve mobility control. The injected chemical on mixing with the formation water can be salted out, precipitate, or form a gel. These phenomena can cause plugging of the formation and render the process ineffective. A critical set of data required is the analysis of major ions and $\mathrm{pH}$ in the formation water as well as all injected fluids. The important ions to be included in the analysis are $\mathrm{Ca}^{++}, \mathrm{Mg}^{++}, \mathrm{Na}^{+}, \mathrm{Fe}^{++}, \mathrm{HCO}_{3}{ }^{-}, \mathrm{CO}_{3}{ }^{--}$, and $\mathrm{SO}_{4}{ }^{--}$. The divalent cations $\mathrm{Ca}^{++}$and $\mathrm{Mg}^{++}, \mathrm{Ba}^{++}$, and $\mathrm{Sr}^{++}$can cause precipitation of alkali, surfactant, and polymer, alter surfactant phase behavior, increase surfactant, alkali and polymer adsorption, and reduce polymer (polyacrylamide) viscosity. $\mathrm{HCO}_{3}^{-}, \mathrm{CO}_{3}^{--}$affect solution $\mathrm{pH}$. $\mathrm{Fe}^{+++}$can react with polymer to form gels and therefore plugs reservoir formation. $\mathrm{Fe}^{+++}$was found to have an immediate effect on polymer injectivity and even small concentrations of $\mathrm{Fe}^{+++}(<5 \mathrm{ppm})$ could produce serious damage to the wellbore (Fletcher, et al, 1992). 


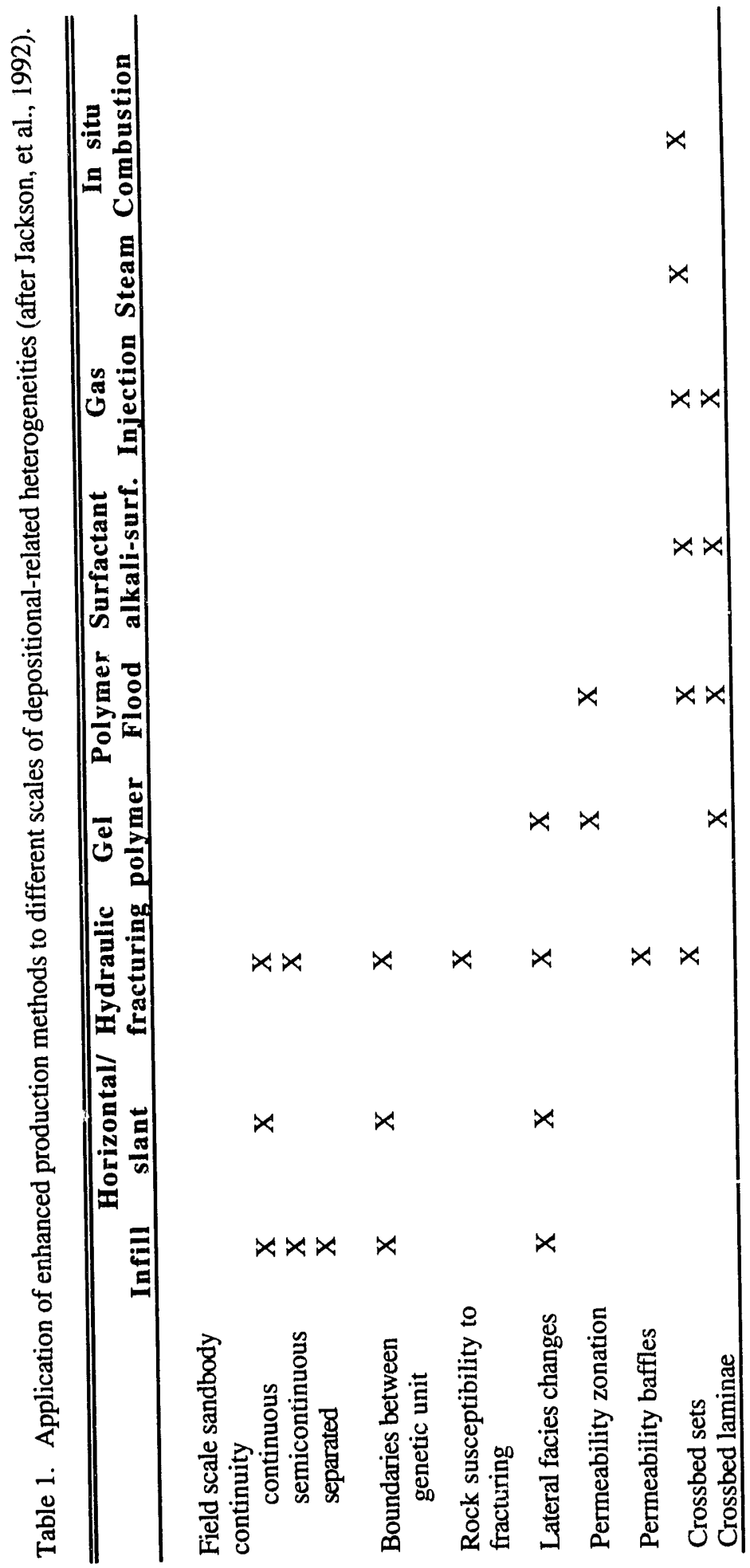


TABLE 2. Distribution of EOR Contraints by Process for selected EOR Projects (after Tham, et al., 1991).

\begin{tabular}{|c|c|c|c|c|c|}
\hline \multirow[b]{2}{*}{ TYPE OF CONSTRAINT } & \multicolumn{5}{|c|}{ EOR PROCESS } \\
\hline & CHEMICAL & GAS & INSITU & STEAM & TOTAL \\
\hline Reservoir Heterogeneity & 6 & 6 & 11 & 7 & 30 \\
\hline Operations & 6 & 9 & 0 & - & 21 \\
\hline Injection Control & 6 & 4 & 3 & - & 13 \\
\hline Downhole Completion & 1 & - & 6 & 6 & 13 \\
\hline Mobility Control & 5 & 6 & 1 & - & 12 \\
\hline Facility Design & 4 & - & 2 & 3 & 9 \\
\hline Process Design & 7 & 1 & 1 & - & 9 \\
\hline Reservoir Conditions & 1 & - & 5 & 2 & 8 \\
\hline Gravity Segregation & - & - & 1 & 6 & 7 \\
\hline Fluid Containment & 2 & - & 1 & - & 3 \\
\hline Reservoir Description & 1 & - & 5 & - & 6 \\
\hline Injectivity & - & 6 & - & - & 6 \\
\hline Chemical Consumption & 5 & - & - & - & 5 \\
\hline Total & 46 & 33 & 43 & 27 & 149 \\
\hline
\end{tabular}

Rock mineralogic composition (quartz, feldspar, gypsum, clay type) and distribution as well as rock cation exchange capacity data is required in designing a chemical EOR project. Quartz and gypsum react with and consume alkali (especially strong alkali) rendering the injected slug ineffective (Mohnot, et al., 1987; Thornton and Radke, 1988; Thornton and Lorenz, 1988; Krumrine and Falcone, 1988). Various clays also react with alkali and adsorb surfactant and polymer, and reduce permeability when less saline water is injected into a reservoir containing swelling clays. High concentrations of more reactive illite/muscovite plus mixed layer clays are detrimental to chemical flooding (Gaida, et al., 1985).

The nature of the pore space is very important in determining the flow and adsorption or retention characteristics of the reservoir rock. The relative absence or presence of clays in pore spaces and pore throats will affect flow behavior and permeability of the reservoir rock. The nature of the pore surfaces and dead-end pores can greatly influence surfactant and polymer depletion (Poettmann and Hause, 1979).
Quantification of floodable net pay, or those parts of the reservoir that will be contacted with injected fluid, is especially important in planning a chemical flooding project. When injecting a relatively expensive chemical, it is important to design the slug for the fraction of the net pay that will be contacted by the formulation. Information on the spatial variations of permeability, porosity and reservoir thickness are essential to identify reservoir compartments and accurate sweep efficiency values. This knowledge will prevent injecting more chemicals than needed for the project.

Crude oil analysis [acid number, equivalent alkane carbon number (EACN) and crude oil asphaltene concentration] is another important data element in the design of surfactant and alkaline flooding processes. Acidic crude oil components react with alkali to form soap that reduces interfacial tension between the brine and crude oil (McCaffery, 1976; Ramakrishnan and Wasan, 1983; Chiwetelu, et al., 1990), thereby improving recovery. The phase behavior of crude oil-surfactant systems is dependent upon the crude oil composition 
EA CN (Puerto and Reed, 1983; Tham and Lorenz, 1981), and asphaltene compounds from crude oil are known to reduce surface activity of surfactant.

\section{Gas EOR}

Gas EOR relies on the injection of gas $\left(\mathrm{CO}_{2}\right.$, methane, or hydrocarbon mixture) to miscibly or immiscibly displace the crude oil. The mechanism by which $\mathrm{CO}_{2}$ miscibly displaces oil is through an extraction of light hydrocarbon from the crude oil. The efficacy for gases to displace a certain crude oil depends strongly on the crude oil composition. Crude oil composition affects phase behavior of the gas $\left(\mathrm{CO}_{2}\right.$, hydrocarbon gas)-crude oil system and, therefore, the ability of the system to reach miscibility. Asphaltene in the crude oil can be precipitated on contact with $\mathrm{CO}_{2}$ causing formation damage and plugging of production wells (Mansoori and Jiang, 1985; Kokal, et al., 1991). Knowledge of the asphaltene content of the crude oil, together with the crude oil composition, is required to predict the precipitation tendency of the crude oil- $\mathrm{CO}_{2}$ system (Chung, 1992).

\section{Thermal EOR}

By introducing heat, through combustion of crude oil in situ (in-situ combustion) or injection of steam (steamflooding or stimulation), the crude oil can be produced as a result of viscosity reduction, solvent bank formation, distillation, wettability reversal, or a combination of all the above mechanisms (Blevins, i990). Crude oil and reservoir rock composition and properties are the most important data required for designing thermal EOR.

Crude oil composition (quantity of low-molecular weight compounds, concentration of polar compounds) affects the recovery efficiency and rate of recovery from steamflooding of light oils, where distillation of light ends is an important recovery mechanism (Schmidt, 1990). Polar compounds affect rock wettability, and steamflood efficiency (Olsen, et al., 1991; Olsen and Crocker, 1991). Crude oil composition also controls the fuel availability and recovery in the in-situ combustion processes (Bae, 1977).

Vanadium, copper, and nickel, common trace components of crude oils, are known to catalyze combustion reactions and thus affect the reaction kinetics (Burger and Sahuquet, 1972; Madden and Maerefat, 1985). Clay compounds tend to promote low temperature oxidation (Vossoughi, et al., 1982). Swelling clay can reduce permeability when less saline injected water (wet combustion), or steam condensate (injected steam or insitu combustion reaction) contact the formation.

In addition, because all thermal EOR processes involve injection of steam or air, which has much lower density than resident oil, the horizontal and vertical permeability and dip of the reservoir will have an important influence on the preferred flow path of injected fluids, and therefore are important parameters that need to be acquired.

Other important information needed to design and implement thermal EOR are the magnitude and orientation of in-situ stresses, the orientation, spacing and conductivity of faults and fractures, and the location of pressure sinks or fluid channels in the reservoir. Despite the importance of these data, they are seldomly available when implementing EOR methods.

\section{Data Density}

Reservoir models are constructed to design the production process and completion pattern for optimum drainage. Rock and fluid data are the building blocks for constructing reservoir models, and these data should be collected to a level sufficient to design accurate reservoir models. In general, the more data collected, the better the reservoir model; but since data collections are expensive and time consuming, an optimum amount of data for successful reservoir modeling and efficient reservoir management should be determined.

The value of data can be assessed as the corresponding loss resulting from poor or incomplete data. Because of reservoir heterogeneities, the problem of incomplete information for modeling often arises. The decision for collecting particular data should be evaluated by comparing the data value to collection cost. It is understandable that the incremental value of additional data usually declines with the amount of data collected, as illustrated in figure 4 , whereas the collection cost of additional data may remain approximately the same; thus, an optimum amount of data can be collected for establishing reservoir models. Figure 4 is only a schematic comparison of possible data value and data collection cost at different data density. Data that should be collected are discussed in this report in two parts: types of data and density of the same type of data.

\section{Types of Data}

Different types of data have different values for constructing reservoir models. Data that have an effect or value on production should be studied carefully. For example, original oil in place (OOIP) is a major factor required in reservoir modeling. Past experience has shown that OOIP cannot be determined without data on porosity, oil saturation, and reservoir size. As a result, measurements of porosity and fluid saturations and determinations of reservoir boundaries should be conducted. Recovery efficiency is also important and original oil saturation, wettability, permeability distribution and sweep efficiency are essential in making 


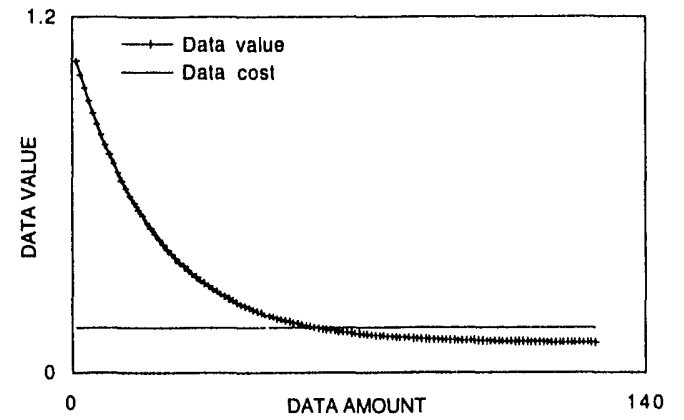

Fig. 4 Comparison of incremental data value and cost.

that prediction. Tremendous efforts are put forward to construct permeability maps for predicting fluid flow paths and recovery efficiencies from reservoirs. Other data affecting recovery efficiency include faults, fractures, baffles, sand continuity, sand lamination, and microscopic heterogeneity (Weber, 1986).

For evaluating data in constructing reservoir models, sensitivity studies provide quantitative comparisons of effects of reservoir properties on production. Numerical simulators are commonly used for studying sensitivities of reservoir parameters to oil production. The reservoir parameters which show larger incremental effects on production have a higher priority than other parameters in data acquisition. Sensitivity studies prior to field development help in selecting critical or important data to be acquired.

The importance of data might vary with production stages or recovery processes. Large-scale heterogeneities such as faults and fractures become more important to production as recovery proceeds from the primary to the secondary (waterflood) stage. Vertical permeability values are more important for production using horizontal wells than vertical wells, or for reservoirs with coning problems, than those without coning problems. Water salinity values, which show little effect on primary production and waterfloods recovery are critical to the success of surfactant flooding in tertiary recovery. Data important to various EOR processes are discussed in previous sections of this report. Numerical simulators are used to obtain quantitative comparisons of the importance of various reservoir parameters at a given stage of reservoir development.

\section{Data Density}

In addition to determining types of data to be acquired, data density (or the amount of data of the same reservoir parameter to be collected) must be determined. Data density, as determined from well controls, will often not permit a deterministic description. This results in a problem of an incomplete data sets. Unfortunately, only limited discussion about data density is available in the literature. As expected, the required data density is a function of genetic sandstone body types and reservoir complexity. Barrier bars are correlatable for wells 3,000 $\mathrm{ft}$ apart in contrast to a well distance of less than $1,000 \mathrm{ft}$ for non-migrating distributary channel-fill sands (Weber, 1986). Based on a few examples, Weber and van Geuns (1990) estimated the well density required for a deterministic layer correlation for three types of reservoirs: 1, 3, and 25 wells per square kilometer drilled in : regular well pattern for layercake, jigsaw-puzzle, and labyrinth reservoirs, respectively. Empirical approaches were used to estimate required well controls or data density.

A quantitative approach is proposed here to test the completeness of data density. To determine the value or contribution resulting from additional data in constructing reservoir models, the basic variogram tool (Journel and Huijbregts, 1978) in geostatistical techniques provides useful information. In general, reservoir parameters have similar values within close proximity, and this similarity decreases with the distance between two sample locations. A variogram describes how the value of a parameter at different locations will vary as a function of spatial location. As shown in a typical variogram in figure 5 , the "variation" of each pair of data increases with the sample distance until it reaches a maximum value at a distance of the correlation range. Any data helping to develop the shape of a variogram within the correlation range are considered to be valuable inputs. Variograms provide key information for mapping reservoir parameters using geostatistical techniques such as kriging. Flow characteristics are often determined by the interpolated reservoir heterogeneities based on variograms.

For example, a variogram of average permeability per well of the Muddy Formation in Unit A of Bell Creek field shows two ranges of correlation lengths: 0.25 and 1.5 miles (Jackson, et al., 1991, Fig. 18). The shorter range is about the distance between wells and reflects the interwell permeability variations. The longer range reflects the permeability change on the order of the width of the sandstone body in Unit A. This variogram indicates that existing well controls are able to distinguish about one-third of the permeability "variations" within a distance of 1.5 miles. Because this correlation range is consistent with the nearby outcrop permeability variation observed (Tornutsa, et al., 1986), where similar mean permeatility and vertical profiles extend 1.6 miles or longer, the perineability variogram of the outcrop can be incorporated into the field data to improve the variogram curve at a distance less than 0.25 mile. 


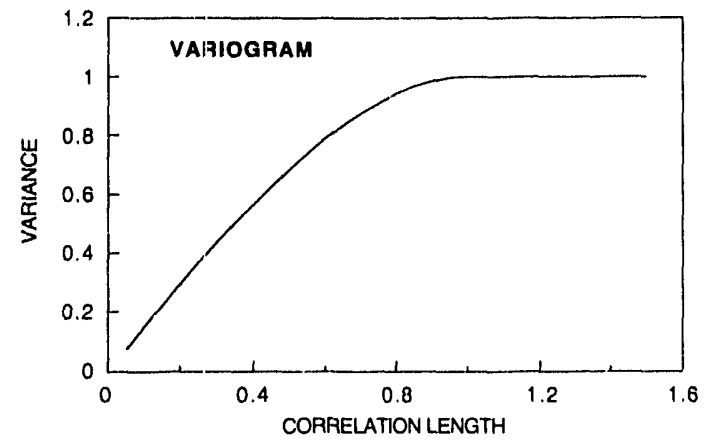

Fig. 5 A typical variogram.

(a)

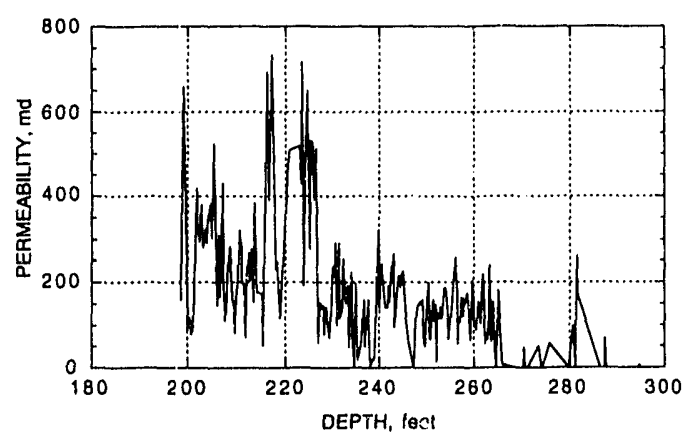

(b)

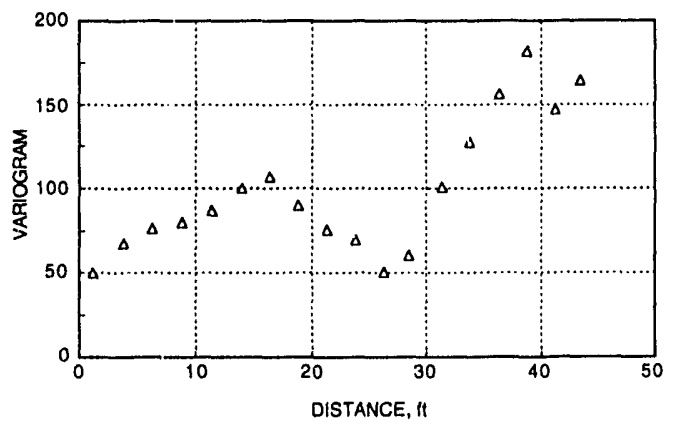

Fig. 6 Permeability profile (a) and variogram (b) of core well No. 2, Almond outcrop, Sweetwater County, WY

The construction of a variogram indicates whether the existing data density is sufficient to provide a spatial correlation for interpolating among control points or control wells. This is the time to stop collecting data. Very often, a variogram may not be fully developed at the smallest interwell distance for some reservoir properties such as rock permeability or shale length. This indicates that the correlation length is smaller than the interwell distance. Furthermore, some reservoir properties such as permeability values are stochastic in nature. The randomness can be found in a scale as small as inches. Fig. 6 shows the permeability measurements (a) and a variogram constructed from the permeability measurements (b), from core well no. 2, drilled from an Almond outcrop 25 miles from Patrick Draw field. The core permeability was measured in an interval of 3 in. using a minipermeameter. The small-scale randomness of permeability shown in the variogram indicates that deterministic modeling is not possible for some reservoir parameters.

The correlation lengths vary from parameter to parameter, from reservoir to reservoir, and even from area to area in the same field. For example, the initial water saturation values in the Monell Unit of Patrick Draw field exhibit a smooth declination from the water-oil contact at the eastern edge $\mathrm{C}_{i}^{\mathrm{f}}$ the Unit to the gas-oil contact at the western edge. In the area east of the low permeability barrier in the Arch Unit, however, no spatial correlation can be found for initial water saturation valıes determined from control wells. This indicates a high degree of heterogeneity for water or oil saturations in this area, and a spatial correlation length is less than the interwell distance. Since the saturation variogram in this area shows no indication of reduction in its variance by reducing the interwell distance by half, collecting additional data by drilling new infill wells is not recommended.

The importance of particular data can be evaluated by a sensitivity study; and the completeness of a data set can be assessed by a plot of a variogram of these data. When a spatial correlation is achieved in the variogram, a reasonable interpolation can be obtained without additional data; therefore, further data acquisition is not necessary.

Researchers may have different requirements for data density. To solve problems, researchers need accurate measurements and enough data for determining causes of observations and deriving hidden correlations. Lessons learned or solutions obtained from research results are transferable to other operations. These "multiplied" values of research activities are therefore justified for a higher density and a better accuracy of data than regular modeling work for one particular reservoir. Research and development of various modeling techniques during the past 10 years are good examples for improving reservoir descriptions. Various geostatistical methods (GomezHernandez and Srivastava, 1990; Haldorsen and MacDonald, 1987; and Hewett, 1986) have improved the interwell-scale interpolation of reservoir heterogeneities from conventional layer-cake models. Intensive sampling of outcrop rocks has provided an insight of distributions of lithology and rock permeability. Studies of outcrops have illustrated the potential and limitation for applying observations from outcrop rocks to the nearby subsurface formations (Tomutsa, et al., 1986). Numerical simulations have explained how small-scale distribution of rock permeability might affect fluid flow and therefore oil recovery in waterfloods (Tomutsa, et al., 1991). The data density required for the above studies may not be justified for modeling a single field project, but it would be valuable for use in other fields for reliable and efficient modeling. 


\section{SUMMARY AND CONCLUSIONS}

The two basic sources of data for reservoir characterization are data from the specific reservoir and from analogous reservoirs, outcrops, and modern environments. Reservoir data can be divided into two broad categories: (1) rock properties (the container), (2) fluid properties (the contents), and (3) rock-fluid interaction. Both static and dynamic measurements are required.

Reservoir characterization requires data on a range of scales from basin and field-scale to pore-size. Field-scale information establishes the spatial framework and the general architecture of the reservoir for describing and predicting smaller scale reservoir geometries and heterogeneities along with their associated petrophysical and fluid-flow properties. Mesoscopic scale information addresses variations of properties within the facies or reservoir units, while microscopic or pore-scale information includes pore size, pore throat, surface roughness, grain size, and sorting.

Outcrop exposures of reservoir rocks provide laterally continuous sampling of rock characteristics, and lateral information on scales not available from reservoir data. Studies of outcrops and analogous modern environments can be a valuable, low-cost source of high quality, geological and petrophysical data. Outcrop studies can provide a wealth of quantitative information on the dimensions and geometries of sandbodies, fluid flow barriers forming compartments, permeability baffles, and the spatial distribution of matrix permeability and porosity. The constraint in applying outcrop data to reservoirs is the ability to determine the degree of transferability of characteristics between different deposits, even within the same depositional system.

Although much of the effort in reservoir characterization is focused on pore- to bedding-scale features, it is the larger scale reservoir architecture that controls the communication between wells and exerts a very strong influence on sweep and recovery efficiency. Regional-scale studies are essential for understanding the origin of the reservoir architecture and predicting the occurrence and location of heterogeneities. Examples are given to illustrate how the understanding of regional scale processes aid the prediction of the location, orientation, and density of reservoir heterogeneity.

The scale of heterogeneities dominating production are different for different field development stages. As field development stages progress from primary to secondary to tertiary recovery, the scale of important heterogeneities generally decreases and is dependent on the EOR process applied. The data required for the development and application of various EOR methods are presented.

The value of data can be assessed as the equivalent loss resulting from poor or incomplete data; however, determination of the optimum data density for reservoir characterization is difficult because often times the value of the data is not known until they are acquired and analyzed. Extensive simulation studies are needed to evaluate the magnitude and direction of errors that can be expected in oil recovery prediction with varying amounts of data. A quantitative approach using the variogram is proposed, where the correlation length is used as a guide to the minimum sampling distance for data collection.

\section{ACKNOWLEDGMENTS}

The authors gratefully acknowledge Tom Burchfield, Mike Madden, Michael Szpakiewicz and Amit Sarkar for reviewing earlier versions of the manuscript and for their helpful comments and stimulating discussions. The guidance and support of Edith Allison, Project Manager, Bartlesville project Office, U.S. Department of Energy is greatly appreciated. Contribution of seismic technology information from Bijon Sharma improved the report. Thanks go to Djaun Grissom for drafting the figures, Viola Rawn-Schatzinger for editorial support and Edna Hatcher for secretarial support.

\section{REFERENCES}

Abbrsxadeh-Dehghani, M. and W. E. Brigham, 1984. Analysis of Well to Well Tracer Flow to Determine Reservoir Layering, J. Pet. v. 36, no. 17, Tech., pp. 1743-1762.

Allison, S. B., G. A. Pope, and K. Sepehmoori, 1991. Analysis of Field Tracers for Reservoir Description. Pet. Science and Engineering, v. 5, pp. 173-186.

Almon, W. R., and D. K. Davies, 1979. Regional Diagenetic Trends in the Lower Cretaceous Muddy Sandstone, Powder River Basin, SEPM Spec. Pub. no. 26, pp. 379-400.

Anthony M. J., T. D. Taylor and B. J. Gallagher, 1981. Fireflooding a High Gravity Crude in a Watered Out West Texas Sandstone. Pres. at the 1981 Permian Basin Oil and Gas Rec. Symposium, Midland, Texas. (fracture and insufficient fuel for combustion), SPE paper 9711.

Bae, J. H., and E. U. Syed, 1988. Glenn Pool Surfactant Flood Pilot Test: Part 2 - Field Operations. SPERE, pp. $771-777$.

Bae, J. H., 1977. Characterization of Crude Oif for Fireflooding Using Thermal Analysis Methods. Soc. Pet. Eng. J., v. 17, pp. 211-218.

Beal, C., 1946. The Viscosity of Air, Water, Natural Gas, Crude Oil and Its Associated Gases at Oil Field Temperatures and Pressures. Trans. AIME, v. 165, pp. 94-115. 
Blackband, S., P. Mansfield, J. R. Barnes, A. D. H. Clague, and S. A. Rice, 1986. Discrimination of Crude Oil and Water in Sand and in Bore Cores with NMR Imaging, SPE Formation Evaluation, v. 1, pp. 31-34.

Blevins, T. R. 1990. Steamflooding in the U.S., A Status Report. J. Pet. Tech., v. 42, no. 5, pp. 548-554.

Brigham, W. E. and M. Abbasxadeh-Dehghani. 1987. Tracer Testing for Reservoir Description, J. Pet. Tech., v. 39 , no. 5, pp. 519-527.

Burger, J. G. and B. C. Sahuquet, 1972. Chemical Aspects of In-Situ Combustion - Heat of Combustion and Kinetics. J. Soc. Pet. Eng. v. 12, no. 5, pp. 410422 .

Carlisle, C. T. et al., 1983. Development of an Improved Method for the Analysis of Pressure Core Samples. Dept. of Energy Report No. DOE/BC-1030916.

Chang, M. M., N. L. Maerefat, L. Tomutsa, M. M. Honarpour, 1988. Evaluation and Comparison of Residual Oil Saturation Determination Techniques. In: SPE Formation Evaluation, v. 3, no. !, pp. 251-262.

Cheruvier, E. and K. W. Winkler, 1987. Field Example Of In Situ Permeability Indication From Full Acoustic Wavetrains. Trans. SPWLA 28th Ann. Logging Symp., pp. NN1-15.

Chiwetelu, C. I., V. Hornof, and G. H. Neale, 1990. A Dynamic Model for the Interaction of Caustic Reagent and Acidic Oils. AIChE. J., 36, v. 3, no. 2, pp. 233-241.

Chung, T. H., 1992. 'Thermodynamic Modeling of Organic Solid Precipitation. To be pres. at the SPE Annual Tech. Conf. and Exhibition to be held in Washington, D.C., Oct. 4-7, SPE paper 24851, pp. 869878.

Cross, T. A., 1991. Field-Scale Reservoir Characterization, in L. W. Lake, H. B. Carroll, Jr., and T. C. Wesson, eds. Reservoir Characterization II, Academic Press, Inc., New York, 726 pp.

Dake, L. P., 1978. Fundamentals of Reservoir Engineering. Elsevier Scientific Publishing Co., NY.

Davis, T. L. and Catherine Lewis, 1990. Reservoir Characterization by 3-D, 3-C Seismic Imaging, Silo Field, Wyoming. The Leading Edge, v. 9, no. 11.

Dodson, C. R. and M. B. Standing, 1944. PressureVolume-Temperature and Solubility Relations for Natural Gas Water Mixtures. Drill. and Prod. Prac., API, p. 173.
Dotson, B. J., R. L. Slobod, P. N. McCreery, and J. W. Spurlock, 1951. Porosity Measurement Comparisons by Five Laboratories. Trans. AIME, v. 192, p. 344.

Doughty D. and L. Tomutsa, 1992. NMR Microscopy for Fluid Imaging at Pore Scale in Reservoir Rock. Joint Society of Core Analysts/Society of Professional Well Log Analysts Symposium, Oklahoma City, Oklahoma. SCA paper 9222.

Doyen, P., 1988. Porosity from Seismic Data-A Geostatistical Approach. Geophysics, v. 53, no. 10, p. 1263-1276.

Earlougher, R. C., Jr., 1977. Advances in Well Test Analysis. SPE Monograph v. 5, Dallas, Texals.

Ensley, R. A., 1989. Analysis of Compressional and Shear-Wave Seismic Data From the Prudhoe Bay Field. The Leading Edge, v. 8, no. 11.

Fletcher, A. J. P., S. P. Lamb, and P. J. Clifford, 1992. Formation Damage From Polymer Solutions: Factors Governing Injectivity. SPE Reservoir Engineering, v. 7, no. 2 , pp. $237-246$.

Frick, T. C., 1962. Petroleum Production Handbook. SPE of AIME, Soc. Pet. Eng., Richardson, Texas.

Gaida, K. H., D. G. Kessel, H. Volz, and W. Zimmerle, 1985. Geological Parameters of Reservoir Sandstones As Applied to Enhanced Oil Recovery. Pres. at the SPE Int'I Symp. on Oilfield and Geochemistry, Phoenix, Arizona.

Goggin, D. J. and M. A. Chandler, 1989. Permeability Transects in Eolian Sands and Their Use in Generating Random Permeability Fields. Pres. at SPE Ann. Tech. Conf. and Exhibit., San Antonio. SPE 19586, pp. 149. 164.

Gomez-Hernandez, J. J. and R. M. Srivastava, 1990. IMIS3D: An ANSI-C Three-Dimensional Multiple Indicator Conditional Simulation Program. Computers \& Geosciences, v. 16, no. 4, pp. 395-440.

Greaves, R. J. and T. J. Fulp, 1987. Three-Dimensional Seismic Monitoring of an Enhanced Oil Recovery Process. Geophysics, v. 52, no. 9, pp. 1175-1187.

Gustavson, E. R., T. A. Ryer, and S. K. Odland, 1988. Stratigraphy and Depositional Environments of the Muddy Sandstone, Northwestern Black Hills, Wyoming. Wyoming Geological Association, Early Science Bull., v. 20 , pp. $49-60$. 
Haldorsen, H. H. and D. Chang, 1985. Notes on Stochastic Shales, From Outcrop to Simulation Model. Reservoir Characterization Conference, Dallas, Texas, NIPER 1985.

Haldorsen, H. H. and L. W. Lake, 1982. A New Approach to Shale Management in Field-Scale Models Pres. at 57th Ann. Tech. Conf. and Exhibit. SPE paper 10976.

Haldorsen, H. H, and C. L. MacDonald, 1987. Stochastic Modeling of Underground Reservoir Facies (SMURF). Paper SPE 16751 SPE Annual Technical Conference and Exhibition, Dallas, TX.

Hassler, G. L., 1944. Methods and Apparatus for Permeability Measurements. U.S. Patent No. 2,345,935.

Heaviside, J., 1991. Measurement of Relative Permeability in Interfacial Phenomena in Petroleum Recovery', N.R. Morrow ed. Surfactant Science Series v. 36, Marcel Dekker, pp. 377-411.

Hertzog, R., L. Colson, B. Seeman, M. O'Brien, H. Scott, D. McKeon, P. Wraight, J. Grau, D. Ellis, J. Schweitzer, and M. Herron, 1987. Geochemical Logging With Spectrometry Tools. Society of Petroleum Engineers, Dallas, Texas. SPE paper 16792 , 447-460.

Hewett, T. A., 1986. Fractal Distributions of Reservoir Heterogeneity and Their Influence on Fluid Transport. Presented at the SPE Ann. Tech. Conf. and Exhibit., New Orleans, Louisiana. SPE paper 15386.

Honarpour, M. M. and S. M. Mahmood, 1988. Relative-Permeability Measurements: An Overview. J. Pet. Tech, v. 40, no. 8, pp. 963-966.

Honarpour, M.M. and D. R. Maloney, 1990. Relative Permeability Technology and Applications. Pres. at the Fourth Annual Technical Conference of the Soc. of Core Analysts, SCA paper 9008 v. 2, 11 p.

Honarpour, M. M., Schatzinger, R. A., M. J. Szpakiewicz, S. R. Jackson, B. Sharma, L. Tomutsa, and M. M. Chang, 1990. Integrated Methodology for Constructing A Quantified Hydrodynamic Model For Application To Clastic Petroleum Reservoirs. Dept. of Energy Report No. NIPER-439 (DE90000211).

Honarpour, M. M., M. J. Szpakiewicz, R. A. Schatzinger, L. Tomutsa, and H. B. Carroll, Jr., 1988. Integrated Geological/Engineering Model for Barrier Island Deposits in Bell Creek Field, Montana. Pres, at SPE/DOE Enhanced Oil Recovery Symp., Tulsa, Oklahoma. SPE/DOE paper 17366, pp. 491-512.
Honarpour, M., M. Szpakiewicz, B. Sharma, M. M. Chang, R. Schatzinger, S. Jackson, L. Tomutsa, and N. Maerefat, 1989. Integrated Reservoir Assessment and Characterization. Department of Energy Report No. NIPER-390 (DE89000743), 336 p.

Honarpour, M. M. and L. Tomutsa, 1990. InjectionProduction Monitoring: An Effective Method for Reservoir Characterization. Pres. at SPE/DOE 7th Symposium on Enhanced Oil Recovery, Tulsa, Oklahoma, SPE/DOE paper 20262, pp. 1-24.

Jackson, J. A., 1984. Nuclear magnetic resonance well logging. The Log Analyst v. 25 (5), pp. 16-30.

Jackson, S. R. and L. Tomutsa, 1991. Reservoir Characterization -- State of the Art Review in Research Needs to Maximize Economic Producibility of the Domestic Oil Resource. Part 1 Literature Review and Areas of Recommended Research. NIPER-527 (DE92001001), pp. 143-172.

Jackson, S. R., L. Tomutsa, M. Szpakiewicz, M. M. Chang, M. M. Honarpour, and R. A. Schatzinger, 1991. Construction of a Reservoir Model by Integrating Geological and Engineering Information - Bell Creek Field, A barrier/Strandplain Reservoir, in L. W. Lake, H. B. Carroll, Jr., and T. C. Wesson, eds. Reservoir Characterization II, Academic Press, Inc., New York. pp. 524-556..

Jackson, S. R., R. A. Schatzinger, V. Rawn-Schatzinger, M. K. Tham, M. M. Chang, 1992. General Geological and Production Characteristics of Deltaic Reservoirs with Annotated Bibliography of Selected References. Dept. of Energy Report EPR/OP-92/14, 77 p.

Johnson, E. F., D. P. Bossler, and V. O. Naumann, 1959. Calculation of Relative Permeability from Displacement Experiments. Trans. AIME, v. 216, pp. 370-372.

Jorgensen, D. W., F. G. Ethridge, and S. A. Schumm, 1992. Patterns of Sedimentation in Rivers Disturbed by Active Tectonics. AAPG Annual Convention Program with Abstracts, Calgary, Canada, p. 61.

Journel, A. G. and C. J. Huijbregts, 1978. Mining Geostatistics, Academic Press, London.

Klinkenberg, L. J., 1941. The Permeability of Porous Media to Liquids and Gases. API Drill. and Prod. Prac., v. 200 , pp. $200-213$. 
Kokal, S., J. Najman, S. G. Sayegh, and A. George, 1991. Asphaltene Precipitation During Enhanced Recovery of Heavy Oils by Gas Injection. Pres. at CIM/AOSTRA Tech. Conf., Banff, Canada. CIM/AOSTRA paper 91-10.

Kortekaas, T. F. M., 1985. Water/oil Displacement Characterisitics in Cross-Bedded Reservoir Zones: SPE paper 12112 , pp. 1-7.

Krumrine, P. H. and J. S. Falcone, Jr., 1988. Rock Dissolution and Consumption Phenomena in an Alkali Recovery System. SPERE.3 (1), pp 62-68.

Lake, L. W., H. B. Carroll, Jr., and T. C. Wesson, eds., 1991. Reservoir Characterization II, Academic Press, San Diego, 726 p. al., 1991

Lorenz, P. B., J. C. Trantham and D. R. Zornes, 1984. A Postflood Evaluation of the North Burbank Surfactant/Polymer Pilot. Pres. at the SPE/DOE Fourth Symposium on Enhanced Oil Recovery held in Tulsa, Oklahoma. SPE/DOE paper 12695, pp 197-210.

Lowry, P, and A. Raheim, 1991. Characterization of Delta Front Sandstones From a Fluvial Dominated Delta System. NIPER/DOE Second International Reservoir Characterization Technical Conference, Dallas, Texas, pp. 665-676.

Luffel, D. L., and R. V. Randall, 1960. Core Handling and Measurement Techniques for Obtaining Reliable Reservoir Characteristics. Pres. at the Formation Evaluation Symposium, Houston, Texas. SPE paper 1642.

Madden, M. P. and H. Maerefat, 1985. The Effects of Metals on In Situ Combustion Processes. Pres. at the 1st International Symposium on Enhanced Oil Recovery (published in symposium proceedings), Maracaibo, Venezuela.

Maloney, D.R., A. Brinkmeyer, and M. Honarpour, 1990. Relative Permeabilities and Other Characteristics of 700-Millidarcy, Fired Berea Sandstone. NIPER-496

Mahmood, S., D. Doughty, L. Tomutsa, and M. M. Honarpour, 1990. Pore Level Fluid Imaging Using High Resolution Nuclear Magnetic Resonance Imaging and Thin Slab Micromodels. Pres. at Society of Core Analysts 4th Conference, Dallas, Texas. SCA paper 9024.

Mansoori, G. A. and T. S. Jiang, 1985. Asphaltene Deposition and Its Role in Enhanced Oil Recovery Miscible Gas Flooding. Pres. at the 3rd European Conf. on Enhanced Oil Recovery, Rome. Italy.
Martinsen, R., 1992. The Muddy Sandstone: A Complex Product of Fluctuating Sea Leel and Syndepositional Tectonics, AAPG Annual Convention Program with Abstracts, Calgary, Canada p. 82.

McCraffery, F. G., 1976. Interfacial Tensions and Aging Behavior of Some Crude Oils Against Caustic Solutions. J. Can. Pet. Tech. v. 15 pp. 71-74.

Melrose, J. C. and C. F. Brandner, 1974. Role of Capillary Forces in Determining Microscopic Displacement Efficiency for Oil Recovery by Waterflooding. J.Can.Pet.Tech. v. 13, no. 4, pp. 54-62.

Miall, A. D., 1988. Reservoir Heterogeneities in Fluvial Sandstones - Lesson from Outcrop Studied. AAPG Bulletin v. 72 , no. 6 pp. 682-697.

Mohnot, S. M., J. H. Bae, and W. L. Foley, 1987. A Study of Mineral-Alkali Reactions. SPERE 2(4) pp. $653-663$

Monicard, R. P., 1984. Properties of Reservoir Rocks: Core Analysis. Gulf Publishing Co., Houston, Texas.

Murphy, R. P., W. W. Owens, and D. L. Dauben, 1973. Well Logging Method. U.S. Patent No. 3,757,575.

National Petroleum Council, 1984. Enhanced Oil Recovery.

Nations, J. F., 1974. Lithology and Porosity From Acoustic Shear Waves Transit Time Relationships. SPWLA 156th Annual Logging Symp., Q.

Oak, M. J., 1990. Three Phase Relative Permeability of Berea Sandstone. J. Pet. Tech., v. 42, no. 8, pp. 10541061.

Ohno, K., T. Nanba, and R. N. Horne, 1985. Analysis of an Interwell Tracer Test in a Depleted Heavy Oil Reservoir. Pres. at the 1985 California Regional Meeting held in Bakersfield, California. SPE paper 13672, pp. 843-856.

Olsen, D. K. and M. E. Crocker, 1991. Evaluation of Articially Wetted Surfaces for Use in Laboratoty Steamflood Experiements. Pres. at the UNITAR/UNDP 5th International Conference on Heavy Oil and Tar Sands, Caracas, Venezuela.

Olsen, D. K., M. E. Crocker, P. S. Sarathi, and J. Bentancourt, 1991. Effects of Elevated Temperature on Capillary Pressure and Wettability, Pres, at UNITAR/UNDPV International Conference on Heavy Oil and Tar Sands, Caracas, Venezuela, Aug 4-9, 1991, paper 110. 
Opportunities to Improve Oil Productivity in Unstructured Deltaic Reservoirs. January 29-30, 1991. Technical Summary and Proceedings of the Technical Symposium held in Dallas, Texas. Dept. of Energy Paper No. BC-91/6/SP.

Park, A., 1984. Sponge Coring Improves Data Quality. American Oil and Gas Reporter, v. 24, pp. 27-29.

Poettmann, F.H. and W. R. Hause, 1979. A Practical Look at Micellar-Polymer Flooding - Part 1. Petroleum Engineer International v. 51, no. 11, pp. 24-36.

Priority of Geoscience Research Areas, Workshops, Discussion Group \#4, 1989. Pres. at NIPER/DOE Second International Characterization Technical Conference, Dallas, Texas. L. W. Lake, H. B. Carroll, T. C. Wesson Co-Chairmen.

Puerto, M. C. and R. L. Reed, 1983. A Three-Parameter Representtion of Surfactant/Oil/Brine Interaction. SPE J. August, v. 23, pp. 669-682.

Pullin, N., L. Matthews and K. Hirsche, 1987. Techniques applied to Obtain Very High Resolution 3-D Seismic Imaging at an Athabasca Tar Sands Thermal Pilot. The Leading Edge. v. 6, no. 12.

Ramakrishnan, T. S. and D. T. Wasan, 1983. A Model for Interfacial Activity of Acidic Crude Oil/Caustic Systems for Alkaline Flooding. SPE J., v. 23, pp. 602. 612 .

Ramey, H. J., 1990. Advances in Practical Well Test Analysis, Pres. at the 65th Ann. Tech. Conf. and Exhibit. New Orleans, Louisiana, SPE paper 20592, pp. 665-676.

Raza, S. H., 1990. Data Acquisition and Analysis: Foundaional to Efficient Reservoir Management. pres. at the 65th Ann. Tech. Conf. and Exhib., New Orleans, Louisiana. SPE paper 20749, pp. 349-353.

Richardson, J. E., et al., 1973. Methods for Determining Residual OIl Saturation with Pulsed Neutron Capture L.ogs, J. Pet. Tech., pp. 593-606.

Ringrose, P. S., K. S. Sorbie, F. Feghi, G. E. Pickup and J. L. Jensen, 1991. Relevant Reservoir Characterization: Recovery Process, Geometry and Scale. European IOR-Symposium Proceeding in Stavanger, Norway, pp. 15-25.

Robertson, J. D., 1989. Reservoir Management Using 3 D Seismic Data, The Leading Edge.
Ruijtenberg, P. A., R. Buchanan, and P. Marke, 1990. Three-Dimensional Data Improve Reservoir Mapping, J. Pet. Tech., v. 42, no. 1, pp. 22-25, 59-61.

Ruzyla, K., 1986. Characterization of Pore Space by Quantitative Image Analysis, SPE Formation Evaluation, v. 1, pp. $389-398$

Saleri, N. G., R. M. Toronyi and D. E. Snyder, 1991. Data and Data Hierarchy. Pres. at the Middle East Oil Tech. Conf. and Exhib. held in Manama, Bahrain, SPE Paper 21369, pp. 279-292.

Sattler, A. R., 1984. The Multiwell Experiment Core Program, II. praper SPE 12854, SPE Unconventional Gas Recovery Symposium, Pittsburgh.

Schatzinger, R. A., M. J. Szpakiewicz, S. R. Jackson, M. M. Chang, B. Sharma, and M. K. Tham, 1992. Integrated Geological-Engineering Model of Patrick Draw Field and Examples of Similarities and Differences Among Various Shoreline Barrier Systems. NIPER-575.

Schmidt, R. L.,1990. Thermal Enhanced Oil Recovery - Current Status and Future Needs. Chemical Engineering Progress, January, pp. 47-59.

Shurr, G. W., 1992. Landsat E- pression of Laramide Deformation in the Williston Basin, Southwestern North Dakota. AAPG Annual Convention Program with Abstracts, Calgary, Canada p. 119.

Singhal, A. K., G. Nieuwenburg, L. Degdick, and M. Roach, 1989. Insights on Reservoir Heterogeneities and Performance of Waterflood at the Bone Creek Unit Obtained from Interwell Tracer Interpretations. Pres. at the Third Technical Meeting of the South Saskatchewan Section, The Petroleum Society of CIM, held in Regina, 25027. Paper No. 23.

Stone, H. L., 1970. Probability Model for Estimating Three-Phase Relative Permeability. J. Pet. Tech. v. 22, no. 2, pp. 214-218.

Surdam, R. C., and H. P. Heasler, 1992. The Regional Pressure Regime in Cretaceous Sandstones and Shales in the Powder River Basin. AAPG Annual Convention Program with Abstracts, Calgary, Canada, p.,127, pp. 159-182, color plates pp. 330-333.

Szpakiewicz, M., K. McGee, and B. Sharma, 1987. Geological Problems Related to Characterization of Clastic Reservoirs for Enhanced Oil Recovery. SPE Formation Evaluation, v. 2, no. 4, p. 449-460. 
Szpakiewicz, M., R. Schatzinger, M. Honarpour, M. Tham, and R. Tillman, 1989. Geological Engineering Evaluation of Heterogeneity, Petrophysical Properties and Productivity of Barrier Island/Valley Fill Lithotypes in the Bell Creek Field; Muddy Sandstone, Powder River Basin, Montana. Rocky Mountain Assoc. Geologists 1989 Symposium, Sandstone Reservoirs of the Rocky Mountains.

Tatham, R. H. and P. L. Stoffa, 1976. Vo/Vs - A Potential Hydrocarbon Bearing Indicator. Geophysics, v. 41 , no. 5, p. 837-849.

Teufel, L. W., and J. C. Lorenz. 1992. Control of Fracture-Reservoir Permeability by Spatial and Temporal Variations in Stress Magnitued and Orientation, AAPG Annual Convention Program with Abstracts, Calgary, Canada, p. 131.

Tham, M. K., et al., 1991. Research Needs to Maximize Economic Producibility of the Domestic Oil Resource. Part II - EOR Field Case Histories. Dept. of Energy Report No. Report NIPER-527 (DE92001001). $521 \mathrm{p}$.

Tham, M. K. and P. B. Lorenz. 1981. The EACN of a Crude Oil: Variation with Cosurfactant and Water Oil Ratio. Pres. at the 1981 European Symposium on Enhanced Oil Recovery, Bournemouth, England, Sept. 21-23.

Thornton, S. D. and P. B. Lorenz, 1988. Mineral Alkali Reactions Under Dynamic Conditions. Dept. of Energy Report No. NIPER-340 (DE98001253).

Thornton, S.,D. and C. J. Radke, 1988. Dissolution and Condensation Kinetics of Silica in Alkaline Solutions. SPERE 3(2) pp. 743-752.

Tomutsa, L., A. Brinkmeyer and C. Raible, 1988. Determining Petrophysical Properties of Reservoir Rocks by Image Analysis. Dept. of Energy Report NIPER-378 (DE89000734), 27.

Tomutsa, L., M. M. Chang, and S. Jackson, 1991. Application of Outcrop Data for Characterizing Reservoirs and Deriving Grid-Block Scale Values for Numerical Simulation. Pres. at the 3rd International Reservoir Characterization Conference, Tulsa, Oklahoma.

Tomutsa, L., S. R. Jackson, and M. Szpakiewicz, 1986. Geostatistical Characterization and Comparison of Outcrop and Subsurface Facies: Shannon Shelf Sand Ridges. Pres. at SPE 56th Calif. Reg. Meeting, Oakland, California. SPE paper 15127.

Tomutsa, L., S. Mahmood, A. Brinkmeyer, and M. Honarpour, 1990. Application of Integrated Pore to
Core Image Analysis to Study Fluid Distribution in Reservoir Rocks. Pres. at SPE Annual Tech. Conf. and Exhibit., New Orleans, Louisiana, SPE paper 20478, pp. 137-148.

Van De Graaft, W. J. E. and P. J. Ealey, 1989. Geologic Modeling for Simulation Studies. AAPG Bull. v. 73, no. 11 , pp. 1436-1444.

Venuto, P. B., 1989. Tailoring EOR Processes to Geologic Environments. World Oil, v. 208, pp. 61 -68.

Vossoughi, S., G. P. Willhite, W. P. Kritikor, I. M. Guvenir and Y. El Shoubary, 1982. Automation of an In-Situ Combustion Tube and Study of the Effects of Clay on the In-situ Combustion Process. SPE Jour., v. 22 , no. 4 , pp. 493-502.

Weber, K. J., 1986. How Heterogeneity Affects Oil Recovery. Reservoir Characterization, L.W.Lake and H.B. Carrol Jr. (eds), Academic Press Inc., Orlando, Florida, pp.487-544.

Weber, K. J. and L. C. van Geuns, 1990. Framework for Constructing Clastic Reservoir Simulation Models. J. Pet. Tech, v. 42, no. 10 , pp. 1248-53, 1296-97.

Weimer, R. J., 1984. Relationship of Unconformities, Tectonics, and Sea-level Changes, Cretaceous of Western Interior, U.S.A., AAPG Memoir 26, pp. 7-35.

Weimer, R. J., J. J. Emmer, C. L. Farmer, L. O. Anna, T. L. Davis, and R. L Kdney, 1982. Tectonic Influence on Sedimentation, Early Crtaceous, East Flank Powder River Basin, Wyoming and South Dakota. Colorado School of Mines Quarterly, v. 77 no. 4. 61 p.

Weimer, R. J., C. A. Rebne, T. L. Davis, 1988 Geologic and Seismic Models, Muddy Sandstone, Lower Cretaceous, Bell Creek-Rocky Point Area, Powder River Basin, Montana and Wyoming. Wyoming Geological Association Guidebook. 39th Field Conference, pp. 161. 178.

Wellington, S. L. and H. J. Vinegar, 1987. X-Ray Computerized Tomography, J. Pet. Tech., v. 39, no. 8, pp. 885-898.

Worthington, P. F., 1991. Reservoir Characterization at the Mesoscopic Scale, in Lake, L. W., H. B. Carroll, Jr., and T. C. Wesson, eds. Reservoir Characterization, II, pp. 123-165.

Zake, S., Abou Zeid and Sherif H El Bishlawy, 1990. 3D Seismic Interpretation in Jarn Yaphour Field, Abu Dhabi, J. Pet. Tech., v. 42, no. 6, pp 700-709. 

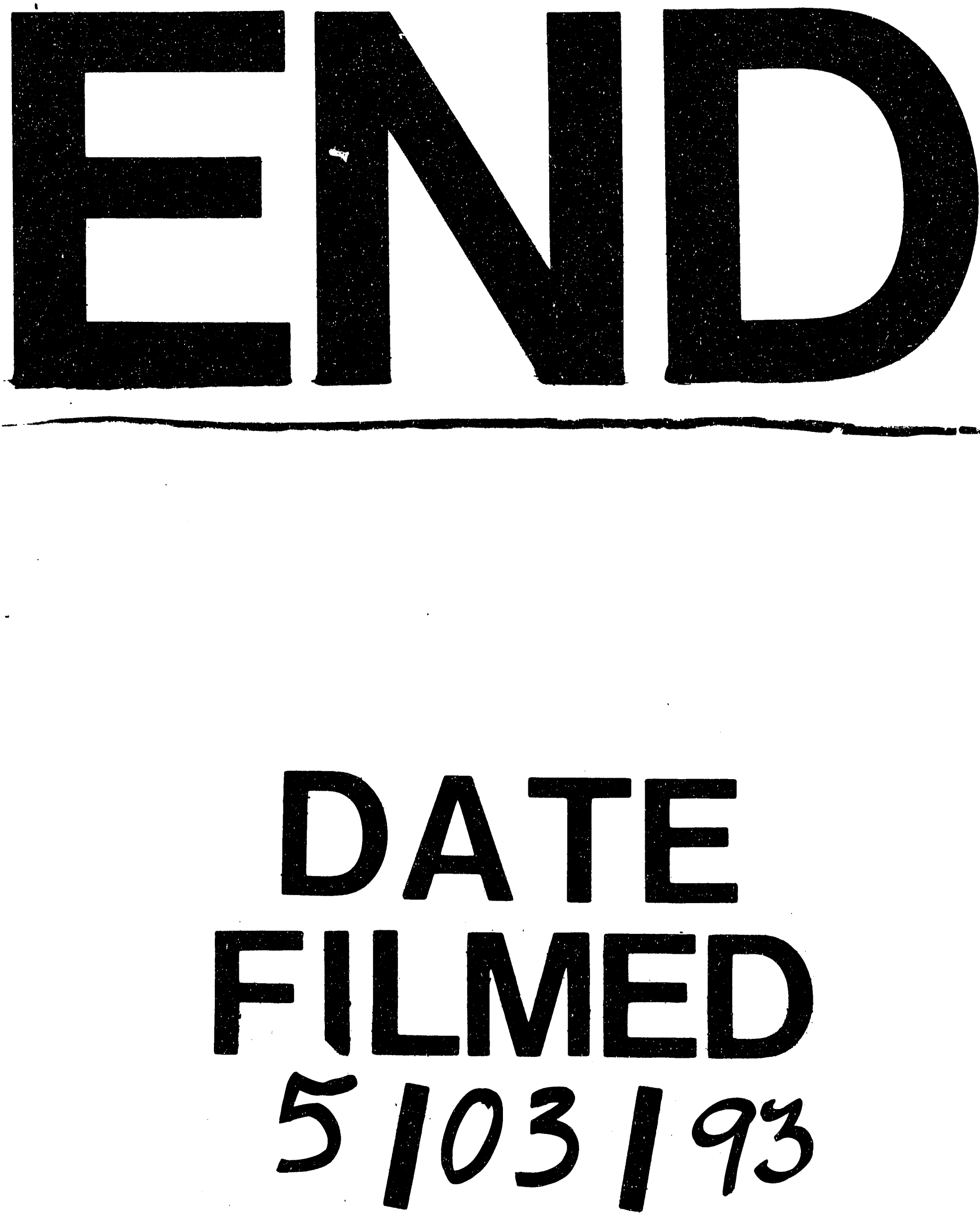
' 